\title{
Application of Fractional Flow Theory for Analytical Modeling of Surfactant Flooding, Polymer Flooding, and Surfactant/Polymer Flooding for Chemical Enhanced Oil Recovery
}

\author{
Lei Ding ${ }^{1, *(\mathbb{D})}$, Qianhui $\mathrm{Wu}^{2}$, Lei Zhang ${ }^{2}$ and Dominique Guérillot ${ }^{1, *(1)}$ \\ 1 Department of Petroleum Engineering, Texas A\&M University at Qatar, P.O. Box 23874, Doha, Qatar \\ 2 College of Petroleum Engineering, China University of Petroleum (East China), Qingdao 266580, China; \\ WU.QIANHUI.UPC@gmail.com (Q.W.); upc_zhanglei@163.com (L.Z.) \\ * Correspondence: lei.ding@qatar.tamu.edu (L.D.); dominique.guerillot@qatar.tamu.edu (D.G.)
}

Received: 25 May 2020; Accepted: 29 July 2020; Published: 4 August 2020

\begin{abstract}
Fractional flow theory still serves as a powerful tool for validation of numerical reservoir models, understanding of the mechanisms, and interpretation of transport behavior in porous media during the Chemical-Enhanced Oil Recovery (CEOR) process. With the enrichment of CEOR mechanisms, it is important to revisit the application of fractional flow theory to CEOR at this stage. For surfactant flooding, the effects of surfactant adsorption, surfactant partition, initial oil saturation, interfacial tension, and injection slug size have been systematically investigated. In terms of polymer flooding, the effects of polymer viscosity, initial oil saturation, polymer viscoelasticity, slug size, polymer inaccessible pore volume (IPV), and polymer retention are also reviewed extensively. Finally, the fractional flow theory is applied to surfactant/polymer flooding to evaluate its effectiveness in CEOR. This paper provides insight into the CEOR mechanism and serves as an up-to-date reference for analytical modeling of the surfactant flooding, polymer flooding, and surfactant/polymer flooding CEOR process.
\end{abstract}

Keywords: Buckley-Leverett theory; fractional flow theory; polymer flooding; surfactant flooding; surfactant/polymer flooding; chemical enhanced oil recovery; Welge method

\section{Introduction}

It is generally acknowledged that only approximately one-third of the crude oil present in known reservoirs can be economically produced after secondary recovery, i.e., water flooding or gas flooding [1-3]. Compared with developing new oilfields and drilling new wells, improving oil recovery from known resources by Chemical-Enhanced Oil Recovery (CEOR) is less risky and has attracted great interest, especially when the oil price is high [2].

Although a variety of fluids can be injected into the reservoir, the underlying mechanisms can be categorized into three principles [1,3]. The first one is lowering the mobility ratio by polymer flooding, thermal flooding, or in situ upgradation of crude oil $[4,5]$. The second approach is to increase the capillary number/bond number/trapping number by reduction of interfacial tension (IFT) to ultralow value $\left(<10^{-2} \mathrm{mN} / \mathrm{m}\right)[6,7]$. The third mechanism is wettability alteration by alkali, surfactant, or nanoparticles [8,9]. Wettability is largely a function of rock mineralogy [2], saturation history [10], salinity [11,12], crude oil property [13,14], potential determining ions (PDI) [15], and $\mathrm{pH}$ [16]. It has been reported that intermediate wet (or mixed wet) may result in the most efficient oil recovery efficiency by water flooding [17]. 
Polymer flooding is the most widely used CEOR method and accounts for a significant amount of incremental oil recovery worldwide [18]. Polymer flooding is most preferable for oil reservoirs with low temperature, low salinity, and low hardness [3,5]. By adding polymer, the areal and vertical sweep efficiency can be greatly improved. However, it was generally acknowledged that the residual oil saturation is not notably decreased after polymer flooding. This is primarily because at a typical reservoir flow rate, the injection of polymer under field operations does not usually increase the capillary number enough to reduce the water-flooded residual oil saturation. Recently, it has been reported that the residual oil saturation may be decreased under certain circumstances by (1) an early injection of polymer [19]; or (2) using viscoelastic polymer [20,21]. Polymer may suffer from chemical degradation, thermal degradation, and mechanical degradation that could limit its effectiveness in the field application [18].

Adding surfactant to injected water to reduce oil/water IFT and/or alter wettability and thereby increase recovery is not a new idea. The main functions of surfactants are to reduce interfacial tension and alter the wettability [22]. It requires not only reaching ultralow IFT to mobilize the water-flooded residual oil and form a continuous oil bank, but also demands maintaining low IFT at the displacement front to prevent the remobilized oil from being trapped by capillary forces [23,24]. It has been generally accepted that the achievement of ultralow IFT is typically accompanied with the presence of a middle phase microemulsion in surfactant phase behavior tests [2,3]. One challenge of surfactant enhanced oil recovery (EOR) application is to limit its adsorption, or more importantly, surfactant retention $[25,26]$. Mobility control has also been proved to be quite important in designing the surfactant EOR process. By adding polymer and increasing the aqueous phase viscosity, a more stable displacement can be achieved, and the laboratory experimental results for Surfactant/Polymer (SP) flooding has been encouraging [2,27].

Reservoir simulation is a powerful tool to estimate relative risk as well as uncertainty, evaluate reservoir performance, develop an optimized strategy, and forecast oil production [28]. The mainstream of reservoir simulators use finite volume or finite difference methods, which require a wide range of expertise in numerous disciplines, such as geology, petrophysics, physics, chemistry, geochemistry, and numerical analysis [29]. In terms of the reservoir simulation, the physics underlying the CEOR process is complex, and the most dominating factors need to be captured in reservoir simulation [3].

Fractional flow theory has been applied to various EOR process [30], including polymer flooding [31], surfactant flooding [32], surfactant/polymer flooding [33], alkali flooding [34], miscible flooding [35-37], foam flooding [38], low-salinity flooding [39,40], etc. An incomplete summary of literatures deploying Buckley-Leverett theory for the application of surfactant flooding, polymer flooding, and surfactant-polymer flooding are summarized in Table 1.

Table 1. Review of literatures about CEOR modeling using fractional flow.

\begin{tabular}{cccc}
\hline References & Polymer Flooding & Surfactant Flooding & Surfactant Polymer Flooding \\
\hline Lake, 2014 [3] & $\sqrt{ }$ & $\sqrt{ }$ & $\sqrt{ }$ \\
Juárez, 2019 [19] & $\sqrt{ }$ & & \\
Koh, 2018 [20] & $\sqrt{ }$ & & $\sqrt{ }$ \\
Qi, 2018 [21] & $\sqrt{ }$ & $\sqrt{ }$ & $\sqrt{ }$ \\
Pope, 1980 [31] & $\sqrt{ }$ & $\sqrt{ }$ & \\
Larson, 1976 [32] & & $\sqrt{ }$ & \\
Farajzadeh, 2019 [33] & $\sqrt{ }$ & & \\
Rossen, 2011 [41] & $\sqrt{ }$ & $\sqrt{ }$ & \\
Sun, 2019 [42] & $\sqrt{ }$ & & \\
\hline
\end{tabular}

Despite the many simplified assumptions (in Section 2.1), fractional flow theory still plays an important role in validation of numerical models, understanding of recovery mechanisms, and interpretation of transport behavior in porous media [3,31]. It is still capable of predicting trends and properties of displacement that still control behavior when the simplified assumptions are relaxed [31]. Moreover, the numerical issues such as convergence and solution non-uniqueness can be 
readily avoided. With new findings and mechanisms being reported, it is important to revisit and investigate the application of fractional flow theory for CEOR.

This paper provides an up-to-date review of the application of fractional flow theory to surfactant flooding, polymer flooding, and surfactant-polymer flooding. Moreover, the effects of various influencing factors on the transport of chemical components and consequently on final incremental oil recovery are systematically investigated, which provide a sharpened insight into designing a successful CEOR process by using the analytical approach.

\section{Analytical Methods}

\subsection{Assumptions}

The Buckley-Leverett equation is a special case of a general mass conservation equation. Many of the assumptions made in this article are as following: (1) one-dimensional, isotropic, and homogeneous porous media; (2) at most two phases are flowing; (3) local equilibrium exists everywhere; (4) the fluids are incompressible and immiscible; (5) capillary pressure is negligible; (6) dispersion is neglected; and (7) adsorption isotherm only depends on one component and has negative curvature $[3,30]$. With these assumptions, the mass conservation equation reduces to:

$$
\varnothing \frac{\partial S_{j}}{\partial t}+\frac{d \vec{u}_{j}}{d x}=0
$$

where $S_{j}$ is the saturation of phase $j, \varnothing$ is the porosity of porous media, and $\vec{u}_{j}$ is the superficial velocity of phase $j$.

\subsection{Derivation of Buckley-Leverett Equation}

For incompressible and creeping flow, the conservation of momentum can be described by Darcy's law after neglecting the inertial terms.

$$
\vec{u}_{j}=-\frac{\vec{k}}{\mu_{j}} \vec{\nabla} \Phi_{j}
$$

where $\overrightarrow{\vec{k}}$ is the permeability tensor, $k_{r j}$ is the relative permeability of phase $j, \vec{u}_{j}$ is the dynamic viscosity of phase $j$, and $\Phi_{j}$ is the flow potential of phase $j$. We define the fractional flow of phase $j\left(f_{j}\right)$ in Equation (3):

$$
f_{j}=\frac{\vec{u}_{j}}{\sum \vec{u}_{j}}, j=\text { water or oil }
$$

Substituting Equation (2) into Equation (3) and further neglecting the gravity and capillary force, then we will get the simplified fractional flow equation:

$$
f_{\mathrm{w}}=\frac{\frac{k_{r \mathrm{w}}}{\mu_{\mathrm{w}}}}{\frac{k_{\mathrm{w}}}{\mu_{\mathrm{w}}}+\frac{k_{r \mathrm{o}}}{\mu_{\mathrm{o}}}}
$$

Substituting Equation (4) into Equation (1), we will get the Buckley-Leverett equation at one dimension, where $\vec{u}_{t}$ is the total superficial velocity.

$$
\frac{\partial S_{j}}{\partial t}+\frac{\vec{u}_{t}}{\varnothing} \frac{\partial f_{j}}{\partial x}=0, j=\text { water or oil }
$$


The dimensionless time and distance are defined in Equation (6):

$$
t_{D}=\frac{\vec{u}^{B C} t}{\varnothing L}, x_{D}=\frac{x}{L}
$$

where $\vec{u}^{B C}$ is the total superficial velocity at boundary condition and $\vec{u}^{B C}=\sum \vec{u}_{j}$. Rearranging Equation (5), we will get the dimensionless form of the Buckley-Leverett equation (Equation (7)):

$$
\frac{\partial S_{j}}{\partial t_{D}}+\frac{\partial f_{j}}{\partial x_{D}}=0, j=\text { water or oil }
$$

Equation (7) is the first-order hyperbolic partial differential equation (PDE), which can be solved by the method of characteristics (MOC).

\section{Results and Discussions}

It should be noted that the results demonstrated in this article are largely dependent on the selection of relative permeability curves and fluid viscosity. However, the main conclusions obtained from this article are still applicable. One can revise the corresponding section of the code (in Supplementary Materials) if the relative permeability curves are readily available.

\subsection{Water Flooding}

Oil recovery efficiency is a function of sweep efficiency and displacement efficiency, which is subsequently a function of mobility ratio $\left(M=\frac{k_{r w} \mu_{o}}{k_{r o} \mu_{w}}\right)$ and residual oil saturation, respectively [3]. The Corey model is applied to correlate the relative permeability and water saturation in this article, as illustrated in Equations (8) and (9) [43]. The parameters for the Corey model are listed in Table 2, which represents a mixed wet or weakly water-wet porous media [44]. The water viscosity and oil viscosity are $0.5 \mathrm{mPa} \cdot \mathrm{s}\left(\right.$ at $60^{\circ} \mathrm{C}$ ) and $72 \mathrm{mPa} \cdot \mathrm{s}$ (conventional crude oil), respectively. The effect of oil viscosity on water flooding efficiency will also be investigated with the help of Buckley-Leverett theory.

$$
\begin{gathered}
k_{r j}=k_{r j}^{0} S_{E j}{ }^{n_{j}}, j=\text { water or oil } \\
S_{E j}=\frac{S_{j}-S_{r j}}{1-\sum_{j=1}^{n p} S_{r j}}, j=\text { water or oil }
\end{gathered}
$$

where $k_{r j}$ is the relative permeability, $k_{r j}^{0}$ is the endpoint relative permeability, $S_{E j}$ is the normalized saturation, $n_{j}$ is the Corey exponent, and $S_{r j}$ is the residual/connate saturation of phase $j(j=w$, water phase, or 0 , oil phase). For water wet porous media, $S_{r w}$ is equal to the connate water saturation, while $S_{r o}$ is the water-flooded residual oil saturation. The relative permeability curves of oil and water are illustrated in Figure 1a, and the calculated fractional flow curve as a function of water saturation based on Equation (4) is shown in Figure 1b. The fractional flow curve is a typical "S" shape curve, and the dimensionless saturation velocity is equal to the derivative of the fractional flow curve based on Equation (10) [30,31].

$$
\left(\frac{d x_{D}}{d t_{D}}\right)_{d s=0}=\frac{d f_{w}\left(S_{w}\right)}{d S_{w}}=v(S)
$$

Table 2. Corey model parameters for water-oil two-phase relative permeability.

\begin{tabular}{cccccccc}
\hline \multicolumn{7}{c}{ Water-Oil Two-Phase Relative Permeability } \\
\hline$k_{r w}^{0}$ & $k_{r o}^{0}$ & $S_{r w}$ & $S_{r o}$ & $n_{w}$ & $n_{\boldsymbol{o}}$ & $\mu_{w}$ & $\mu_{\boldsymbol{o}}$ \\
\hline 0.14 & 0.40 & 0.15 & 0.24 & 4 & 2 & 0.5 & 72 \\
\hline
\end{tabular}




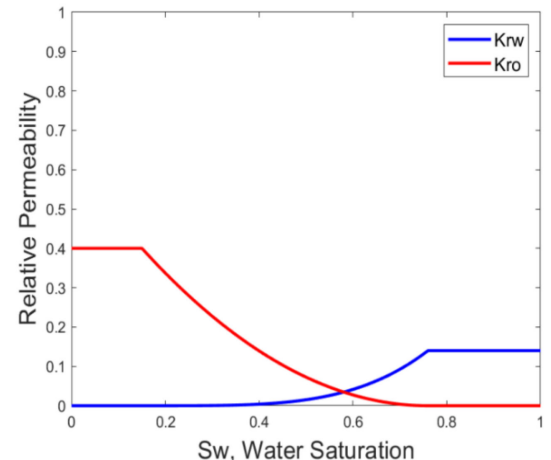

(a)

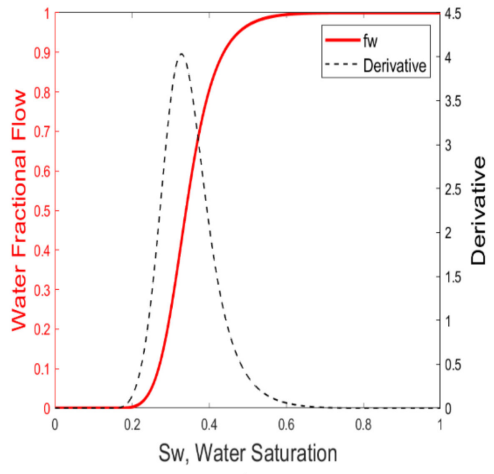

(b)

Figure 1. (a) Water-oil two-phase relative permeability; and (b) Fractional flow of water and its derivative as a function of water saturation based on parameters in Table 2.

\subsubsection{General Approach}

Using the expression of saturation velocity in Equation (10), the saturation profile can be plotted as the dashed line in Figure 2a. However, this solution is non-physical due to the existence of saturation discontinuity. The Buckley-Leverett solution [30] to this problem is to define the saturation discontinuity at the shock front $\left(X_{D, \text { shock }}\right)$ by making a mass balance between areas ahead, at the front

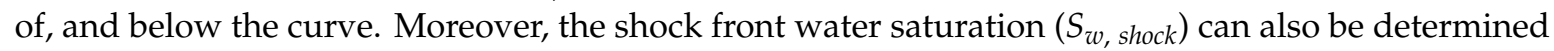
graphically by drawing a tangent line from the initial condition (I.C.) to the fractional flow curves [45]), as shown in Figure $2 b$. The dimensionless velocity of the shock front can be determined by Equation (11). At the contact between the shock and continuous saturation distribution, these velocities must be equal, given by:

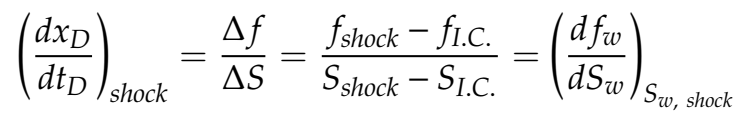

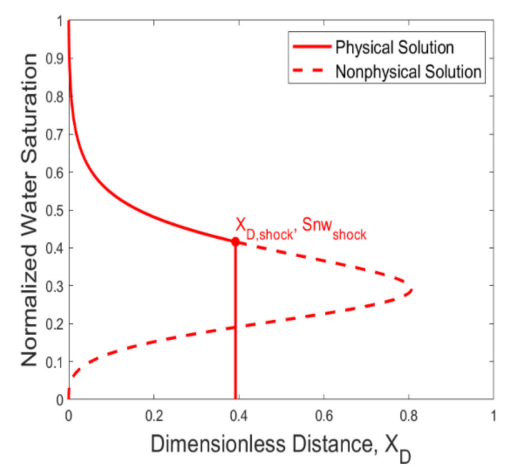

(a)

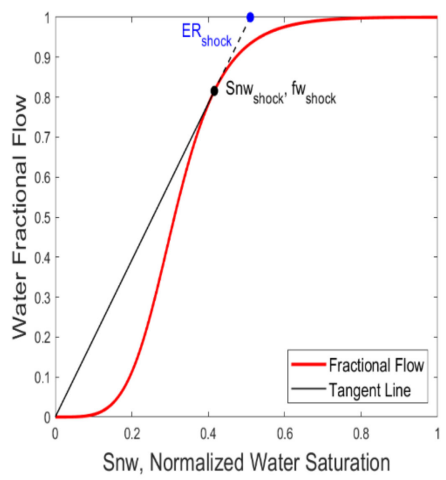

(b)

Figure 2. Determination of the shock front by (a) Material balance and (b) Welge graphical method, parameters are listed in Table 2.

The Welge [45] method also provides a graphical method for the calculation of oil recovery at water breakthrough and beyond. Here, we define the recovery factor as the recovery efficiency, which is normalized with respect to the original water-flooded movable oil in place, as indicated in Equation (12).

$$
E_{R}=\left\{\begin{array}{c}
t_{D}, t<t_{B T} \\
S_{n w}-\frac{\left(f\left(S_{n w}\right)-1\right)}{\frac{d f}{d S}\left(S_{n w}\right)}, t>t_{B T}
\end{array}\right.
$$


where $E_{R}$ is the recovery factor, $t_{D}$ is the dimensionless time, $t_{B T}$ is the time at water breakthrough, and $S_{n w}$ is the normalized water saturation (same as $S_{E j}$ in Equation (9) in this article). The trajectory for constant water saturation in a distance-time domain is shown in Figure 3. Since we are assuming constant initial and boundary conditions, the trajectories are straight lines originating from $(0,0)$. The relationship between the history diagram and profile diagram can be illustrated in a plot for the trajectories of constant water saturation. The profile is a plot of the saturation at fixed time, while an effluent history is the plot of saturation or fractional flow at $X_{D}=1$. The Welge approach also provides a graphical method for calculation of the oil cut history and cumulative oil recovery at and beyond water breakthrough (Equation (13)). Before water breakthrough, 100\% oil is produced. The breakthrough time expressed in pore volume is the reciprocal of dimensionless shock velocity expressed in Equation (11).

$$
t_{D}=\frac{1\left(X_{D}=1\right)}{\frac{d f}{d S}\left(S_{n w}\right)}
$$

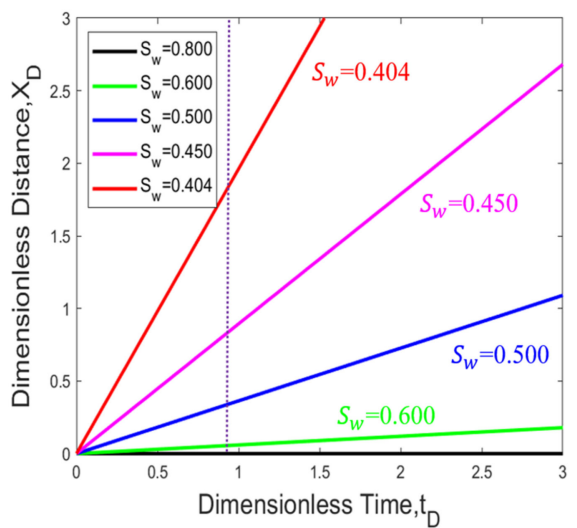

(a)

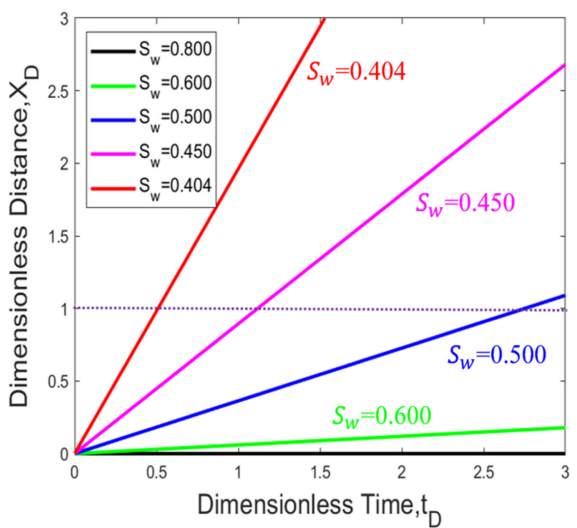

(b)

Figure 3. Trajectory of constant water saturation in distance time diagram; (a) Construction of saturation profile plot, and (b) Construction of effluent history plot.

\subsubsection{Influence of Oil Viscosity}

The influence of oil viscosity on the water fractional flow curve and the shock front is illustrated in Figure 4. The rest of the parameters are the same as those listed in Table 2. The oil viscosity $\left(\mu_{0}\right)$ is 5 $\mathrm{cP}, 72 \mathrm{cP}$, and $1200 \mathrm{cP}$, representing the viscosity of light crude oil, conventional crude oil, and heavy crude oil, respectively.

It can be seen that the slope of the shock front is steeper when the oil viscosity is higher, i.e., the saturation shock transports faster at an elevated mobility ratio. Moreover, the water saturation at the shock front is lower for the higher mobility ratio. There is a region of spreading waves behind the shock front. The water saturation profile at 0.20 pore volume (PV) water injection is illustrated in Figure $4 \mathrm{~b}$. The shock wave is the fastest wave, and ahead of the shock wave is a region of constant state, i.e., the initial condition. The position of saturation can be obtained by integrating Equation (10) in time, as illustrated in Equation (14).

$$
X_{D}=t_{D} \frac{d f_{w}\left(S_{w}\right)}{d S_{w}}, \text { for } S w \geq S w_{\text {shock }}
$$

The effect of oil viscosity on water flooding recovery efficiency in the first 5.0 PV is illustrated in Figure 5a. Moreover, the oil recovery factor decreases with the increasing mobility ratio after injecting the same amount of water in the first 5.0 PV. However, as can be seen in Figure 5b, if an infinite amount of water is injected into the porous media, the remaining oil saturation will be quite close to the residual 
oil saturation for different mobility ratios, despite the fact that more water is needed to be injected to reach the same remaining oil saturation.

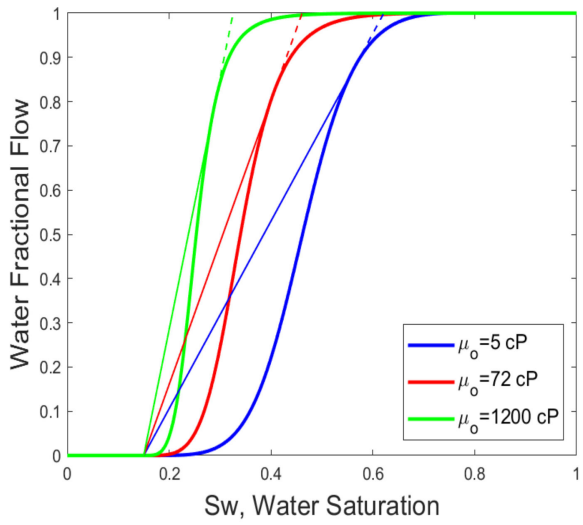

(a)

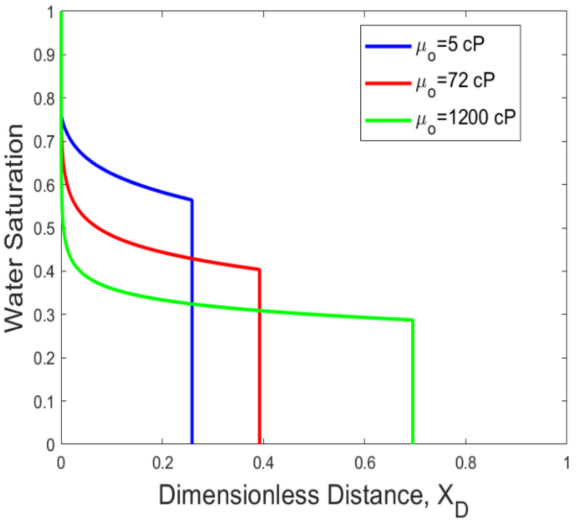

(b)

Figure 4. (a) Water fractional flow as a function of oil viscosity and construction of shock front; and (b) Water saturation profile at $t_{D}=0.20 \mathrm{PV}$ as a function of different oil viscosity during water flooding. The lines in green, red, and blue represent the cases of water flooding with high oil viscosity, moderate oil viscosity, and low oil viscosity, respectively.

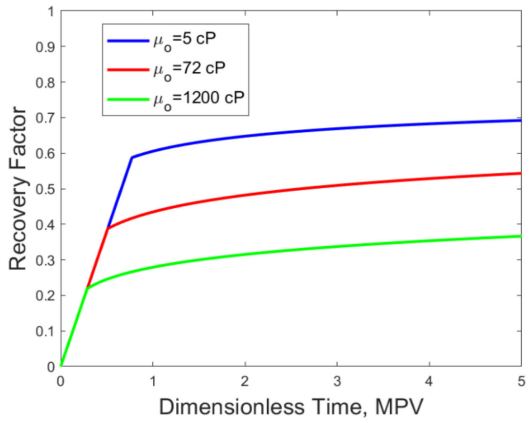

(a)

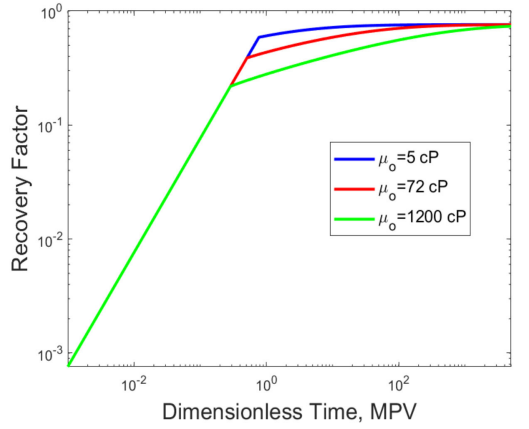

(b)

Figure 5. Oil recovery history at (a) normal scale and (b) logarithm scale as a function of oil viscosity during water flooding. The lines in green, red, and blue represent the cases of water flooding with high oil viscosity, moderate oil viscosity, and low oil viscosity, respectively.

The oil and water cut history up to 5.0 PV water injection for different oil viscosity are illustrated in Figure 6a,b, respectively.

We can see the time when water breakthrough is earlier: at higher oil viscosity, i.e., the higher mobility ratio. The breakthrough time is the time at which the fastest wave (shock front) reaches $X_{D}=1$. The mobility ratio does affect the economics of water flooding. Suppose that the economic limit is $3.0 \%$ oil cut; then, mostly, it would be operated at conditions close to the economic limit under unfavorable mobility ratios. 


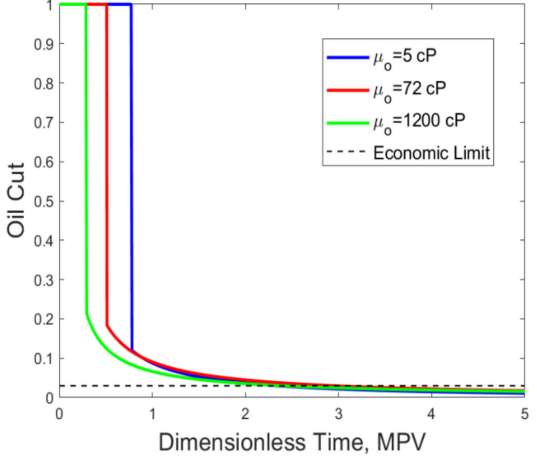

(a)

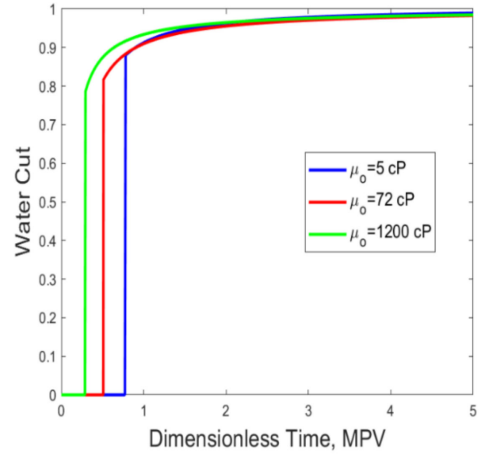

(b)

Figure 6. (a) Water cut history and (b) oil cut history during water injection up to 5.0 PV for different oil viscosity. The lines in green, red, and blue represent the cases of water flooding with high oil viscosity, moderate oil viscosity, and low oil viscosity, respectively.

\subsection{Surfactant Flooding}

The principal mechanism for surfactant flooding is the reduction of IFT between oil and water, and consequently a reduction of residual oil saturation trapped by capillary force [2]. The oil-water relative permeability has been reported to be largely a function of interfacial tension (IFT). In fact, the residual oil saturation can be substantially decreased at low IFT, or more generally, at a high capillary number $\left(N_{c a}\right)$ [46]. In order to reach an analytical solution, we will at first make two further assumptions [31]: (1) the partition of surfactant into oil is negligible; and (2) the presence of middle phase microemulsion is neglected to allow the description of the process by only two phases.

In this demonstration, the relative permeability curves in the presence and absence of surfactant are represented as dashed lines and solid lines respectively in Figure 7a, and the parameters for Corey model correlation are listed in Table 3. It should be noted that the relative permeability curve in the presence of surfactant is taken only to illustrate the impact of surfactant on water fractional flow and final oil recovery. We will further discuss the influence of IFT in Section 3.2.6. Furthermore, high viscosity oil may not be favorable for surfactant flooding; thereby, light oil is used, and the end point mobility ratio is 3.5 in this demonstrated case.

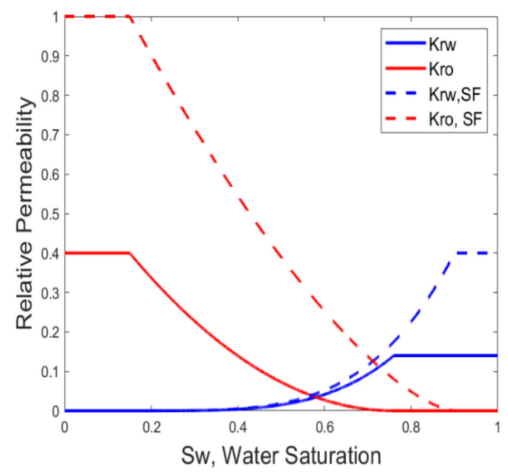

(a)

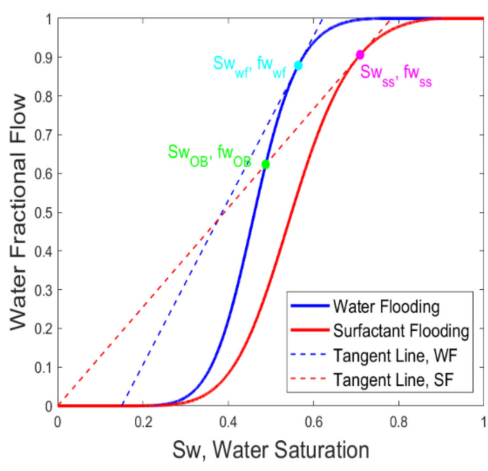

(b)

Figure 7. (a) Water-oil relative permeability curves in the absence and presence of surfactant; and (b) Fractional flow curves in the absence and presence of surfactant (no adsorption, no partition) and construction of the respective shock front for water flooding and surfactant flooding. 
Table 3. Corey model parameters for water-oil two-phase relative permeability in the presence and absence of surfactant.

\begin{tabular}{lccccccc}
\hline \multicolumn{6}{l}{ Water-Oil Two-Phase Relative Permeability in the Absence of Surfactant } \\
\hline$k_{r w}^{0}$ & $k_{r o}^{0}$ & $S_{w c o n}$ & $S_{\text {oirw }}$ & $n_{w}$ & $n_{o}$ & $\mu_{w}$ & $\mu_{o}$ \\
\hline 0.14 & 0.40 & 0.15 & 0.24 & 4 & 2 & 0.5 & 5 \\
\hline \multicolumn{7}{l}{ Water-Oil Two-Phase Relative Permeability in the Presence of Surfactant } \\
\hline$k_{r w}^{0}$ & $k_{r o}^{0}$ & $S_{w c o n}$ & $S_{\text {oirc }}$ & $n_{w}$ & $n_{o}$ & $\mu_{w}$ & $\mu_{o}$ \\
\hline 0.40 & 1.00 & 0.15 & 0.10 & 4.0 & 1.5 & 0.5 & 5 \\
\hline
\end{tabular}

The continuity equation for surfactant or any other component of similar characteristics, i.e., no dispersion and no mass transfer, can be written as:

$$
\frac{\partial\left(\varnothing_{i} S_{w} C_{i}\right)}{\partial t}+\frac{\partial}{\partial t}\left((1-\varnothing) \rho_{s s} A_{i}\right)+\frac{q}{A} \frac{\partial\left(C_{i} f_{w}\right)}{\partial x}=0
$$

where $C_{i}$ is the component $i$ (surfactant) in aqueous phase, $\varnothing_{i}$ is the accessible pore volume of component $i, \rho_{s s}$ is the density of porous media, and $A_{i}$ is the adsorption density of component $i$ per unit mass of rock. Defining an adsorption of component $i$ in units of amount of adsorbed per unit pore volume $\left(\hat{C}_{i}\right)$,

$$
\hat{C}_{i}=\frac{(1-\varnothing) \rho_{s S} A_{i}}{\varnothing}
$$

Substituting Equation (16) into (15), and assuming $\varnothing_{i}=\varnothing$, we derive:

$$
\left(S_{w}+\frac{d \hat{C}_{i}}{d C_{i}}\right) \frac{\partial C_{i}}{\partial t}+\frac{q f_{w}}{A \varnothing} \frac{\partial C_{i}}{\partial x}=0
$$

The continuity equation of water is still the same as Equation (5) after approximating the volume fraction of the surfactant as negligible. The composition velocity of the surfactant will follow:

$$
\left(\frac{d X}{d t}\right)_{d C_{i}=0}=\frac{f_{w}}{S_{w}+D_{i}}
$$

where the general retardation term, $D_{i}$, replaces $\frac{d \hat{C}_{i}}{d C_{i}}$.

The effect of surfactant EOR is represented by the other fractional flow curve constructed using the modified relative permeability curve (color in red) in Table 3. Generally, two saturation shocks form during a surfactant flood [3]. The first shock forms as the oil bank is being developed, where the water saturation increases to its initial value. The second saturation shock forms at the surfactant concentration front, i.e., where the surfactant water contacts the initial water and the surfactant concentration jumps from zero to its injection value. The injected surfactant solution and connate water are completely miscible fluids. However, the final oil saturation ends at $S_{\text {orc }}$ rather than $S_{\text {orw }}$. At the surfactant front, the velocity of the water saturation shock and surfactant composition front must be equal. Therefore, we will have Equation (19),

$$
\frac{f_{w 3}-f_{w 2}}{S_{w 3}-S_{w 2}}=\left(\frac{d f_{w}}{d S_{w}}\right)_{S_{w}=S_{w 3}}=\frac{f_{w s s}}{S_{w s s}+D_{i}} .
$$

\subsubsection{Case I: No Adsorption, No Partition, Continuous Surfactant Injection, Tertiary Flooding}

We will first consider the case of continuous surfactant flooding without adsorption $\left(D_{i}=0\right)$ or surfactant partition. As discussed previously, the relative permeability curve during surfactant flooding was modified due to reduction of IFT. In this demonstration, the initial condition before 
surfactant flooding is water-flooded remaining oil saturation $\left(S w_{i w}\right)$, and the boundary condition is $f_{w}$ $=1$ (continuous surfactant injection). The construction of the oil bank is shown in Figure $8 \mathrm{a}$, and the saturation profile at $t_{D}=0.20 \mathrm{PV}$ is illustrated in Figure $8 \mathrm{~b}$.

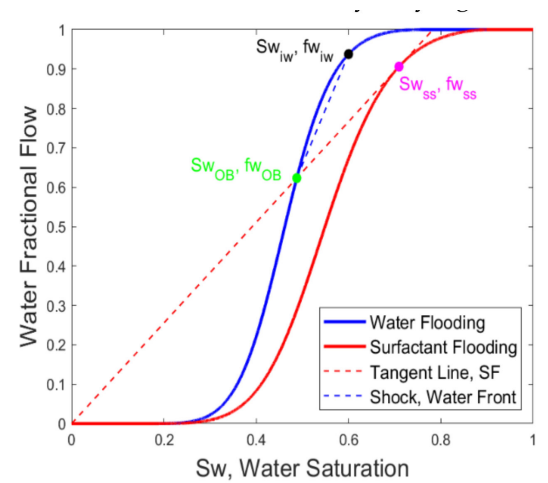

(a)

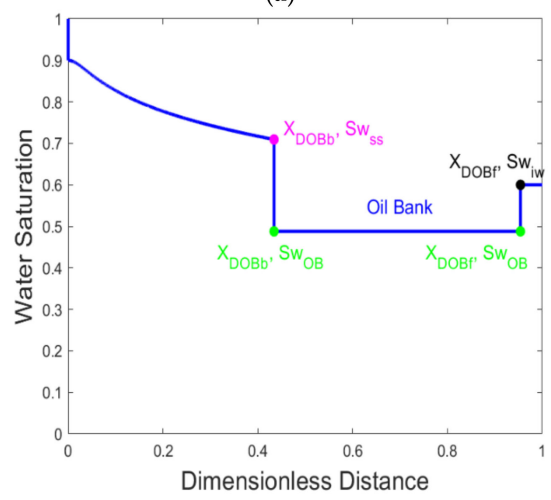

(c)

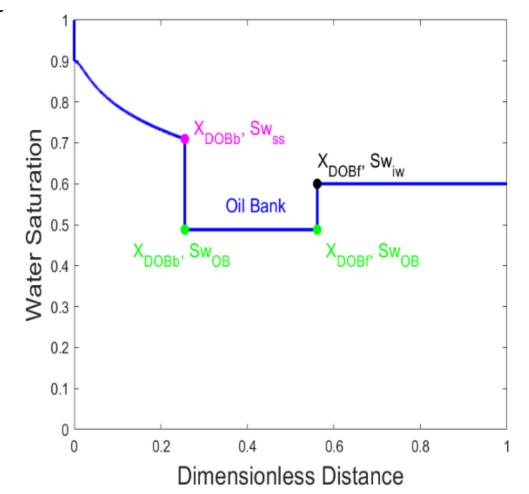

(b)

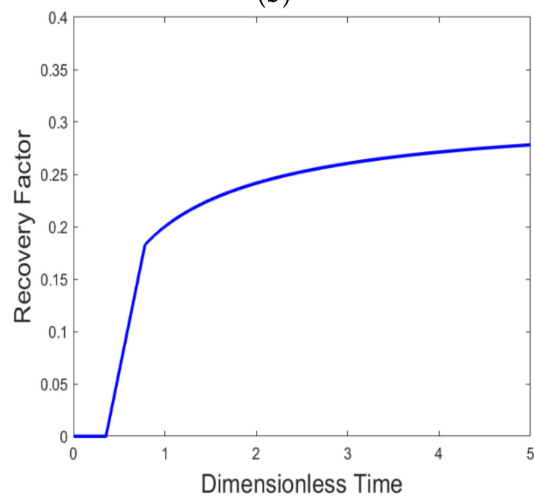

(d)

Figure 8. (a) Construction of shock front; (b) water saturation profile at $t_{D}=0.20 \mathrm{PV}$; (c) water saturation profile at $t_{D}=0.34 \mathrm{PV}$; and (d) cumulative oil recovery during tertiary continuous surfactant flooding, no adsorption, no partition.

A clear oil bank $\left(1-S w_{O B}=0.51\right)$ is formed, and the oil fractional flow $\left(1-f w_{O B}\right)$ is around 0.38 in the oil bank. Behind the surfactant shock $\left(S w_{s s}-S w_{O B}\right)$, there is a region of spreading waves, i.e., oil production tails. The surfactant concentration behind this shock is equal to the injected concentration. Moreover, the size of the oil bank increases with time due to the velocity difference between the front and back of the oil bank, as shown in Figure 8b,c. The cumulative oil recovery during continuous tertiary surfactant flooding is shown in Figure 8d. The oil bank and surfactant bank breakthrough are at $0.36 \mathrm{PV}$ and $0.78 \mathrm{PV}$, respectively. After that, an extended oil tail is produced with oil fractional flow $\left(1-f w_{s s}\right)$ less than 0.10 and then further decreasing with time. It should be noted that the performance of surfactant flooding is largely dependent on the water fraction flow curve in the presence of surfactant, which may vary significantly from the demonstrated case.

\subsubsection{Influence of Surfactant Adsorption}

Ion exchange, surfactant adsorption, and surfactant phase trapping are three major factors for surfactant loss during its transport in porous media [47]. The principle that velocities must be equal at the contact between a pair of miscible fluids recurs in subsequent examples [31]. The solution can be obtained graphically from the point $\left(-D_{i}, 0\right)$ tangent to the surfactant fractional flow curve. Moreover, the solution of Equation (19) gives the values of the oil bank composition. In the example case, the initial condition is water-flooded residual oil saturation, $S w_{i w}$, and the dimensionless retardation factor is 0.20 PV. The graphical construction is shown in Figure 9a. 


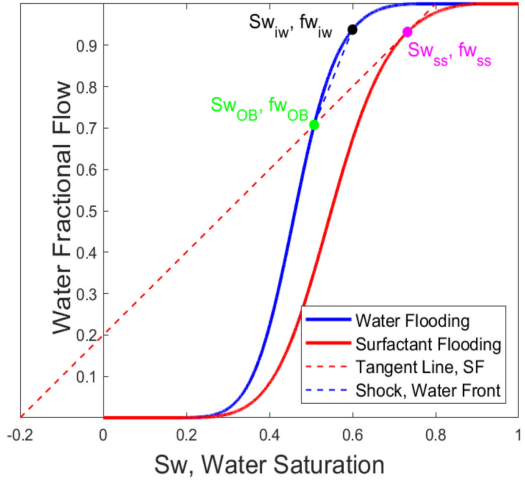

(a)

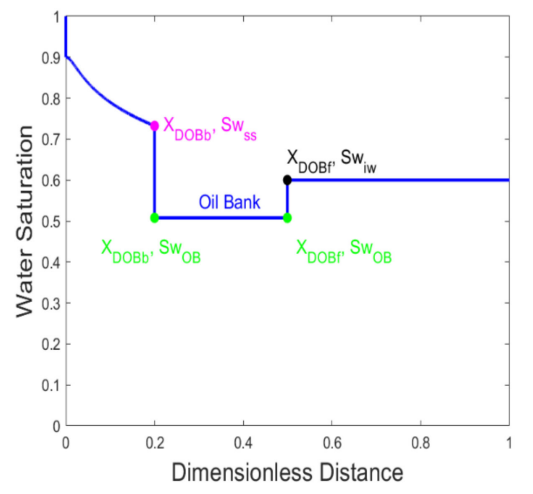

(b)

Figure 9. (a) Construction of shock front; and (b) water saturation profile at $t_{D}=0.2 \mathrm{PV}$ during continuous surfactant injection, with adsorption, $D_{i}=0.20 \mathrm{PV}$, no partition. PV: pore volume.

The calculated water saturation profile at $t_{D}=0.20 \mathrm{PV}$ is illustrated in Figure $9 \mathrm{~b}$, where a large oil bank is still established with oil fractional flow $\left(1-f w_{O B}\right)$ at around 0.29 in the oil bank. There are two shocks formed: the surfactant shock and the front of oil bank. The oil saturation in the oil bank $\left(1-S w_{O B}\right)$ is approximately 0.49 . Behind the surfactant front, there is also a region of spreading waves for water saturation $S_{w}$ larger than $S w_{s s}$.

Figure 10 shows the influence of surfactant adsorption on final oil recovery and the saturation profile at $0.20 \mathrm{PV}$. We can see that the retardation factor can greatly influence the economics of surfactant flooding. If only a limited slug size of surfactant is injection, the retardation effect on surfactant transport would be even more severe [2]. At a higher retardation factor, the surfactant is stripped off from the injection brine, and its surfactant frontal velocity is significantly decreased. Therefore, more surfactant is required to be injected. Consequently, the oil saturation in the oil bank is also much smaller at a higher retardation factor.

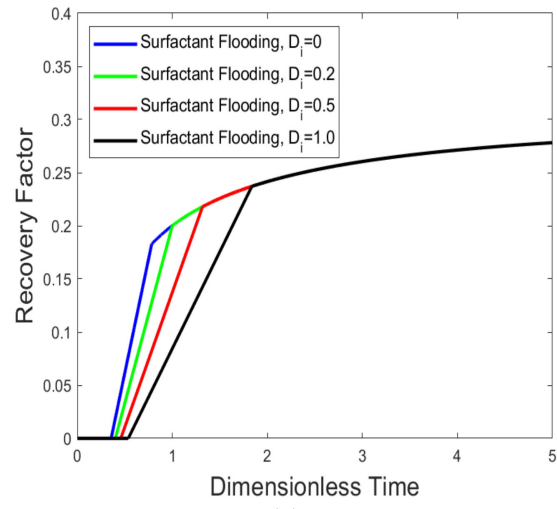

(a)

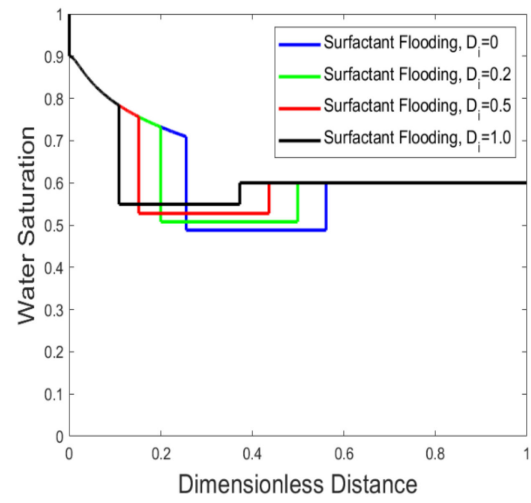

(b)

Figure 10. (a) Incremental oil recovery by surfactant flooding as a function of retardation factor; and (b) saturation profile at $t_{D}=0.2 \mathrm{PV}$ for different retardation factors.

\subsubsection{Influence of Surfactant Partition}

Previously in the context, we assume that the surfactant only transports in the aqueous phase. However, this is generally not correct, since most of the surfactant for EOR can be partitioned between the aqueous phase and the oleic phases [47]. To reach the analytical solution with surfactant partition, we make the following assumptions further in this section:

- $\quad$ Constant partition coefficient: $K_{s o w}=\frac{C_{s o}}{C_{s w}}$;

- Constant phase saturation: $S_{0}=S_{\text {orw }}$; 
- One phase flow: $f_{o}=0$ and $f_{w}=1$;

- No adsorption.

Considering the surfactant partition between oil and water, the continuity equation for surfactant can be written as,

$$
\frac{\partial\left(C_{i w} S_{w}+C_{i o} S_{o}\right)}{\partial t}+\frac{q}{A \varnothing} \frac{\partial\left(C_{i w} f_{w}+C_{i o} f_{o}\right)}{\partial x}=0 .
$$

Substituting $K_{s o w}=\frac{C_{s o}}{C_{s w}}$ into Equation (19), we derive,

$$
\frac{\partial\left(C_{s w} S_{w}+K_{s o w} C_{s w} S_{o}\right)}{\partial t}+\frac{q}{A \varnothing} \frac{\partial\left(C_{i w} f_{w}+C_{i o} f_{o}\right)}{\partial x}=0 .
$$

Equation (21) is equal to Equation (22), after arrangement,

$$
\frac{S_{w} \partial C_{s w}}{\partial t}+\frac{C_{s w} \partial S_{w}}{\partial t}+\frac{K_{s o w} C_{s w} \partial S_{o}}{\partial t}+\frac{K_{s o w} S_{o} \partial C_{s w}}{\partial t}+\frac{q}{A \varnothing} \frac{\partial\left(C_{i w} f_{w}+C_{i o} f_{o}\right)}{\partial x}=0 .
$$

For the special case of constant phase saturation and one phase flow, we will get

$$
\left(S_{w}+K_{s o w} S_{o}\right) \frac{\partial C_{s w}}{\partial t}+\frac{q}{A \varnothing} \frac{\partial C_{i w}}{\partial x}=0 .
$$

The term, $K_{\text {sow }} S_{0}$, is similar to the dimensionless retardation factor, $D_{i}$. Based on the analysis in Section 3.2.2, it can be concluded that a larger propensity for surfactant being partitioned into the oleic phase and (or) a higher oil saturation will result in more severe surfactant retardation during transport in porous media. Furthermore, the oil phase viscosity may be considerably increased if the surfactant is preferable to be partitioned into the oleic phase. Generally, the partition of surfactant into the oleic phase is becoming notable when the salinity is higher. Therefore, a negative salinity gradient is important to mitigate excessive or unexpected surfactant partition/retention into the oil phase [48].

\subsubsection{Influence of Initial Oil Saturation}

Figure 11a illustrates the graphical method to construct the shock fronts for the surfactant and oil bank, while Figure $11 \mathrm{~b}$ plots the water saturation profile at $t_{D}=0.20 \mathrm{PV}$ in terms of secondary recovery.

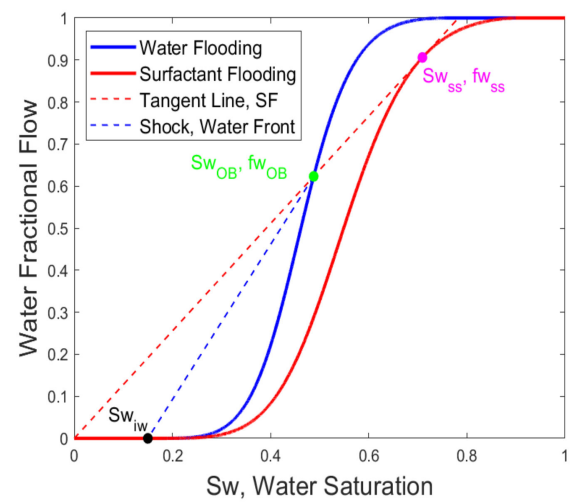

(a)

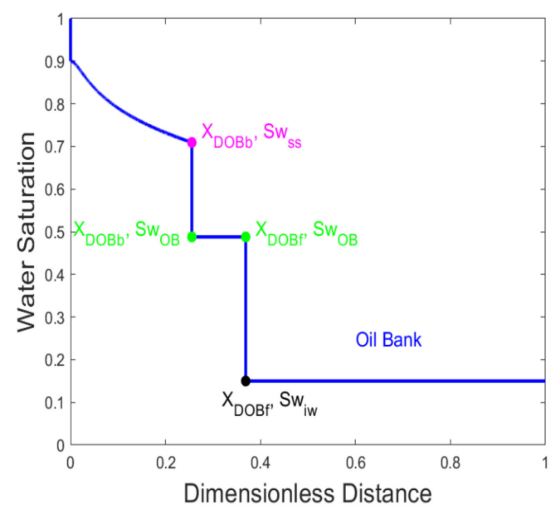

(b)

Figure 11. (a) Incremental oil recovery by surfactant flooding as a function of retardation factor; and (b) saturation profile at $t_{D}=0.2 \mathrm{PV}$ for different retardation factor.

Again, two shock fronts can be developed using the similar approach described in Section 3.2.1. The difference between the secondary recovery and tertiary recovery is that the water saturation jumps from water saturation in the oil bank $\left(S w_{O B}=0.49\right)$ to connate water saturation $\left(S w_{i w}=0.15\right)$ in the secondary case and from $S w_{O B}$ to $\left(1-S_{o r}\right)$ in the tertiary case. It should be noted that for the example 
case, $S w_{O B}$ is smaller than $S w_{w f}$, as shown in Figure $7 \mathrm{~b}$. If it is not the case, there will be a spreading wave between $\left(S w_{O B}\right)$ and $\left(S w_{s}\right)$. We can also see from Figure $11 \mathrm{~b}$ that the initial oil saturation will not influence the back shock of the oil bank, i.e., the surfactant shock. However, the oil production history and the front of the oil bank will be largely depending on the initial oil saturation.

The oil production history for the secondary case is exhibited in Figure 12a. Before water breakthrough $(0.54 \mathrm{PV}), 100 \%$ oil is produced; then, the oil cut is decreased to around 0.38 after the first shock breakthrough. After the second shock breakthrough, the oil cut is sharply decreased to 0.10 and then further decreased as the oil tail comes through. After the injection of 0.78 PV surfactant, the remaining oil saturation is close to the residual oil saturation in both the secondary and tertiary cases (Figure 12b).

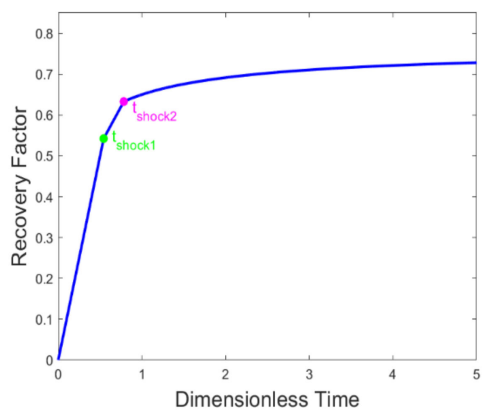

(a)

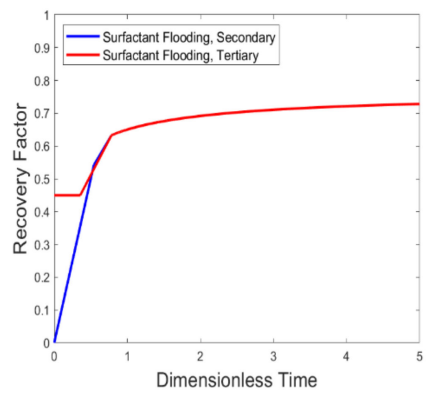

(b)

Figure 12. (a) Cumulative oil recovery history during the secondary recovery process and (b) comparison of cumulative oil recovery during the secondary and tertiary processes for continuous surfactant injection with no surfactant adsorption and no surfactant partition.

\subsubsection{Influence of Injected Surfactant Slug Size}

The analytical solution for surfactant slug injection has been first proposed by Bedrikovetski [49]. In this section, we use a semi-analytical approach developed by Hamid [50]. The viscous fingering effect and adsorption effect are not considered in this example case. The key results are summarized as follows, and more details can be found in the reference [50]. The boundary conditions corresponding to injection of the surfactant slug and the chase water are expressed in Equation (24),

$$
\left\{\begin{array}{c}
C_{S D}=1, S_{w}=1 ; 0<t_{d, \text { total }}<t_{d, \text { slug }} \\
C_{S D}=0, S_{w}=1 ; t_{d, \text { total }}>t_{d, \text { slug }}
\end{array}\right.
$$

where $C_{S D}$ is the normalized surfactant concentration with respect to the injected concentration, and $t_{d, \text { total }}$ and $t_{d, \text { total }}$ are the total dimensionless time (PV) and dimensionless slug size (PV), respectively. The water saturation immediately downstream the water drive discontinuity is $S_{3}$, and immediately upstream, the water drive is $S_{4}$. We define $A$ as,

$$
\frac{t_{d, \text { slug }}}{t_{d, \text { total }}}=f_{3}-S_{3} V_{3}=A
$$

where $f_{3}$ are $f_{3}=f_{w}\left(S_{w}=S_{3}\right)$ and $V_{3}=\frac{d f_{3}}{d S_{3}}$. The discontinuity between the chase water and the polymer slug is found at distance $X_{3}$ from the inlet based on material balance.

$$
X_{3}=V_{3} t_{d, \text { total }}=\frac{A t_{d, \text { total }}}{\mathrm{B}}
$$


$X_{2}$ is the leading edge of the surfactant slug, and there is a rectangular saturation profile of the slug. The size can be determined by,

$$
X_{2}-X_{3}=\frac{t_{d, \text { slug }}}{S_{2}}
$$

where $S_{2}$ is the limiting value of $S_{3}$ (the saturation at the trailing edge of the polymer slug), which can be found by drawing the tangent to the polymer fractional flow curve from the origin, as illustrated in Figure 13a. $f_{2}$ is the water fractional flow at water saturation $S_{2}\left(f_{2}=f_{w}\left(S_{w}=S_{2}\right)\right)$. At the chase water front, the value of $S_{4}$ can be determined graphically from $S_{3}$ at any given time by performing a jump from surfactant oil to the water-oil fractional flow curve $\left(f_{4}=f_{w}\left(S_{w}=S_{4}\right)\right)$.

$$
\frac{F_{w}\left(S_{4}\right)-F_{w}\left(S_{3}\right)}{S_{4}-S_{3}}=\frac{F_{w}\left(S_{4}\right)}{S_{4}}=\frac{F_{4}}{S_{4}}=V_{4}
$$

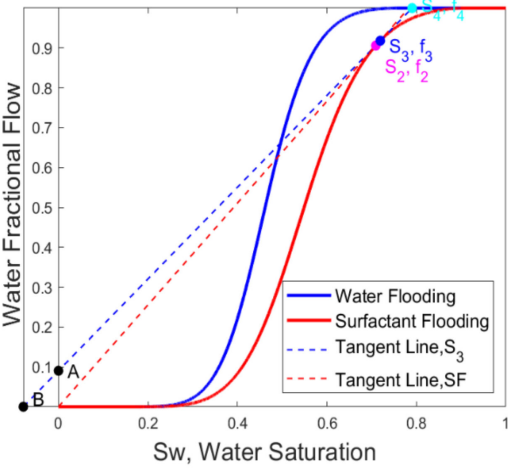

(a)

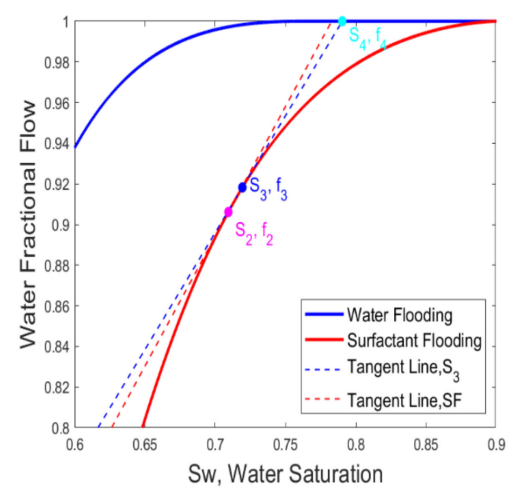

(b)

Figure 13. (a) Determination of the shock front during surfactant slug injection; (b) Magnification of figure (a) for determining shock front location, $t_{d, s l u g}=0.30 \mathrm{PV}, t_{d, \text { total }}=3.32 \mathrm{PV}$.

The analytical solution of slug injection is complicated, since a third discontinuity occurs between the chase water and the trailing edge of the surfactant slug. The third discontinuity does not travel at a constant flow rate, which is different from the first two shocks [50]. The construction of the shock front for surfactant slug injection is shown in Figure 13. Figure 13b is the magnification of Figure 13a near the shock front. A and B are the values corresponding to Equations (25) and (26). In this case, the surfactant slug $\left(t_{d, \text { slug }}\right)$ is $0.30 \mathrm{PV}$, and the total time $\left(t_{d, t o t a l}\right)$ is $3.32 \mathrm{PV}$, i.e., a water injection of $3.02 \mathrm{PV}$. Generally, if there is a step change in the boundary condition, the new set of waves will be set up and may overtake slower waves from the original boundary conditions and cause interference. However, in this case, the surfactant front has a velocity larger than unity, i.e., the velocity of the miscible front [51]. Therefore, the water drive will not catch up with the surfactant front in the surfactant slug.

In the following case, a 0.30 PV slug of water drive is injected after the injection of $0.34 \mathrm{PV}$ of surfactant. At $t_{d, t o t a l}=0.34 \mathrm{PV}$, the construction of the shock front and water saturation profile are illustrated in Figure 14. It can be seen that the slug size does not have a significant influence on recovery efficiency, which may be not physically reasonable in the real case. This is primarily because the effect of viscous fingering [50] or adsorption is not considered in the aforementioned example [51], and the miscible front does not have a velocity that is large enough to catch up with the surfactant front. The other approach to practically evaluate the effect of slug size on surfactant EOR is to utilize the coherence theory, and a detailed description can be found in various publications [52-56]. 


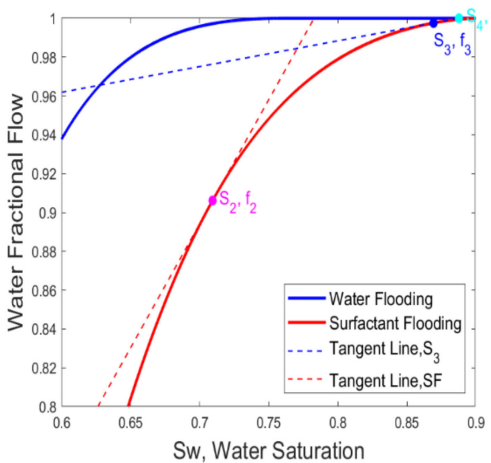

(a)

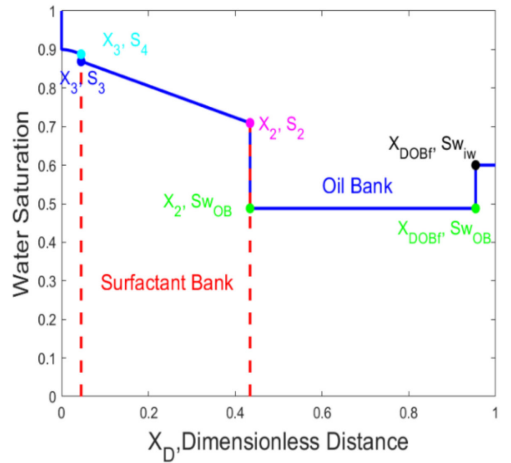

(b)

Figure 14. (a) Determination of the shock front during surfactant slug injection; and (b) water saturation profile and oil bank at $t_{d, \text { total }}=0.34 \mathrm{PV}$, surfactant slug size $t_{d, \text { slug }}=0.30 \mathrm{PV}$.

\subsubsection{Influence of Interfacial Tension}

As mentioned before, the relative permeability curve is largely a function of interfacial tension (IFT), or more generally, capillary number [57]. We use the scaling method proposed by Liu [57], which is essentially equivalent to that used in UTCHEM software (The University of Texas at Austin, Austin, TX, USA) [58]. The water and oil relative permeability curves are hypothesized to follow the Corey model, which is one of the most widely applied models for relative permeability correlation.

Figure 15 discloses the water-oil relative permeability curve and fractional flow of water at different IFT values according to Equations (29)-(32). The relative permeability curve for water flooding at high IFT is the same as shown in Table 2. At ultralow IFT, there is no shock wave, and only spreading waves exist from the boundary condition $\left(f_{w}=1, S_{w}=1\right)$ to the initial condition $\left(f_{w}=0, S_{w}\right.$ $=0$ ), as indicated by the red line in Figure 15b. Moreover, by just adding surfactant and decreasing the IFT, it is not assured that the fractional flow curve of surfactant flooding would move to the right. Therefore, polymer is necessary in most of the cases to provide mobility control [2,31].

$$
\left\{\begin{array}{c}
k_{r j c}=k_{r j c}^{0} S_{j R} E_{j} \\
S_{j R}=\frac{S_{j}-S_{r j c}}{1-S_{r v o c}-S_{r o c}}
\end{array}, j=\right.\text { water or oil }
$$

where $k_{r j c}, k_{r j c^{\prime}}^{0} S_{j R}$, and $E_{j}$ are the relative permeability of phase $j$, the end point relative permeability of phase $j$, the normalized saturation of phase $j$, and the Corey exponent for the relative permeability-water saturation correlation in the presence of surfactant. $S_{r w c}$ and $S_{r o c}$ are the connate water saturation and residual oil saturation in the presence of surfactant respectively, which are a function of IFT.

$$
\left\{\begin{array}{c}
S_{r j c}=0,\left(\gamma_{o w}<0.005 \mathrm{mN} / \mathrm{m}\right) \\
S_{\mathrm{rjc}}=S_{r j} \times\left(1+\frac{\log _{10}\left(\gamma_{o w}\right)}{2.3}\right), 0.005 \mathrm{mN} / \mathrm{m}<\gamma_{o w}<1 \mathrm{mN} / \mathrm{m} \\
S_{r j c}=S_{r j}, \gamma_{o w}>1 \mathrm{mN} / \mathrm{m}
\end{array}\right.
$$




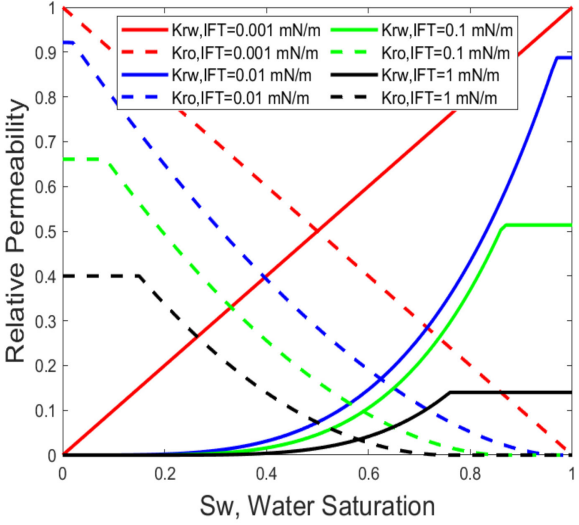

(a)

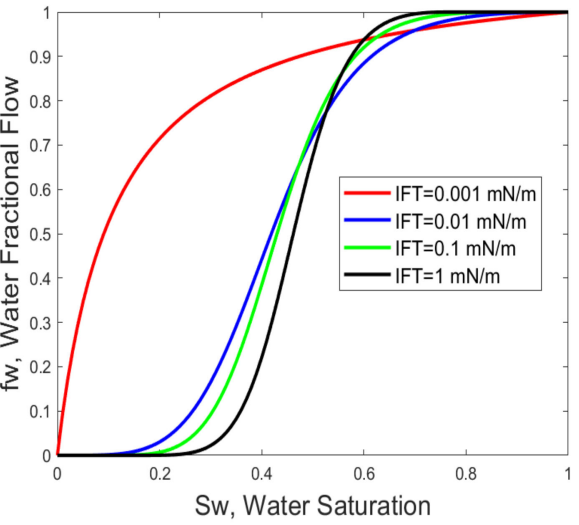

(b)

Figure 15. (a) Water/oil relative permeability; and (b) water fractional flow as a function of water saturation and interfacial tension (IFT).

The end point relative permeability, $k_{r c^{\prime}}^{0}$ and Corey exponent, $E_{j}$, are modified as a function of IFT such that the relative permeability curve at ultralow IFT is diagonal in the relative permeability versus water saturation plot.

$$
\begin{gathered}
k_{r j c}^{0}=k_{r j}^{0}+\left(1-k_{r j}^{0}\right)\left(S_{r j}-S_{r j c}\right) / S_{r j} \\
E_{j}=1.0,\left(\gamma_{o w}<0.005 \mathrm{mN} / \mathrm{m}\right) \\
\left\{\begin{array}{c}
E_{j}=n_{j}+\left(1-n_{j}\right)\left(S_{\mathrm{rj}}-S_{r j c}\right) / S_{\mathrm{rj}}, 0.005 \mathrm{mN} / \mathrm{m}<\gamma_{o w}<1 \mathrm{mN} / \mathrm{m} \\
E_{j}=n_{j}, \gamma_{o w}>1 \mathrm{mN} / \mathrm{m}
\end{array}\right.
\end{gathered}
$$

where $k_{r j}^{0} S_{r j}$, and $n_{j}$ are the end point relative permeability, residual saturation, and Corey exponent of phase $j$ during water flooding at typical brine-water IFT.

\subsection{Polymer Flooding}

Polymer flooding is the most successful chemical EOR process applied in the field so far, accounting for a significant portion of the total incremental oil recovery by chemical EOR [18]. The principal mechanism for polymer flooding is the decrease of mobility ratio by increase of the aqueous phase viscosity, and therefore the issues of viscous fingering, gravity segregation, and channeling could be mitigated by increasing the viscous forces [2,3]. It is preferentially applicable for viscous oil up to at least $200 \mathrm{cP}[2,59]$. However, it is generally acknowledged that the relative permeability curve remains unchanged in polymer flooding under most of the circumstances [33]. For the polymer flooding fractional flow curve, this is always represented by increasing the aqueous phase viscosity. Mostly, the polymer will only transport in the aqueous phase. Therefore, the partition of polymer into oil is hypothesized to be zero in this section.

\subsubsection{Case I: No Adsorption, Continuous Polymer Injection, Tertiary Flooding}

Figure 16a illustrates the fractional flow curve for water flooding and polymer flooding. All the parameters remained the same as in Table 2, and the aqueous viscosity with the polymer is $30 \mathrm{cP}$. The initial condition is $S_{i w}=0.6$, and the boundary condition is continuous polymer injection, $f_{w}=1$ and $\mu_{p}=30 \mathrm{cP}$.

The construction of the shock front and saturation profile at 0.20 PV are exhibited in Figure 16a,b. By precisely performing the same analysis as described before, we find that two shocks form: the oil bank front, behind which the initial water in the system displaces oil and the chemical front behind which the injected chemical pushes the oil toward the outlet. Behind the surfactant shock, it is a region of spreading waves with constant polymer concentration. A clear oil bank still can be formed due to the increase of the aqueous phase viscosity during continuous polymer injection. The oil saturation 
$\left(1-S w_{O B}\right)$ and oil fractional flow $\left(1-f w_{O B}\right)$ in the oil bank are 0.66 and 0.52 , respectively. Moreover, the oil bank breakthroughs are after injecting around 0.51 PV polymer, while the polymer shock breakthroughs are at around $0.70 \mathrm{PV}$. The cumulative oil recovery during continuous polymer injection in the tertiary process is shown in Figure 16c. We cans see that the time required to reach residual oil saturation is significantly shortened at augmented aqueous viscosity with the help of the polymer.

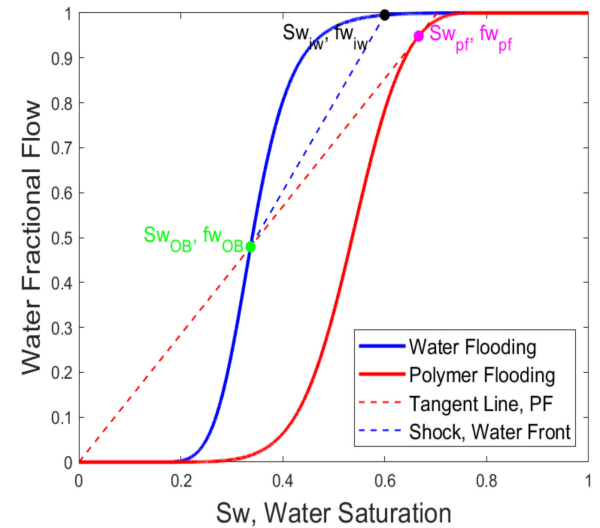

(a)

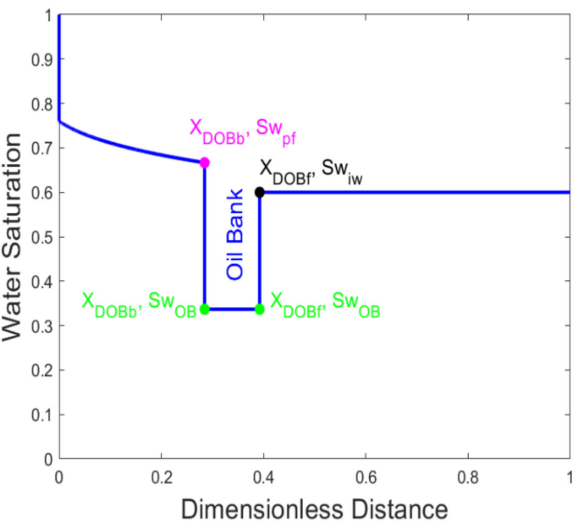

(b)

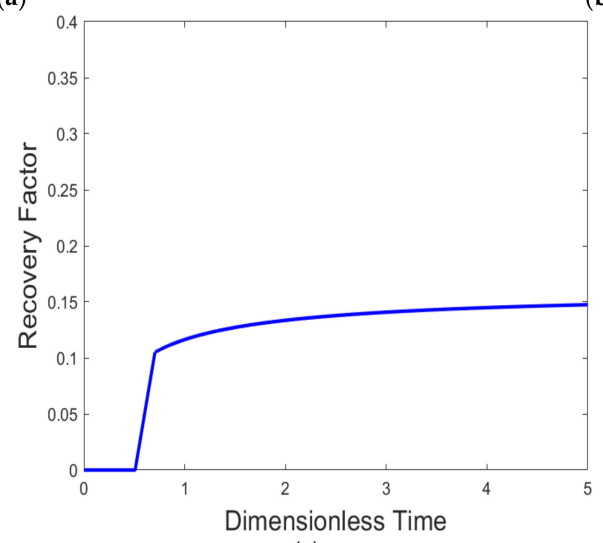

(c)

Figure 16. (a) Construction of shock front; (b) Water saturation profile at $t_{D}=0.20 \mathrm{PV}$; and (c) Cumulative oil recovery for tertiary polymer flooding, continuous injection, no polymer retention.

\subsubsection{Influence of Polymer Viscosity}

The influence of polymer viscosity on polymer flooding efficiency in terms of oil bank saturation and production history are exhibited in Figure $17 \mathrm{a}, \mathrm{b}$ respectively. The rest of parameters are the same as those utilized in Section 3.3.1.

When the polymer viscosity is increased, the displacement is closer to piston-like. Decreasing the polymer viscosity does not modify the oil bank saturation appreciably, yet it decreases the size of the oil bank significantly. Moreover, a larger slug of polymer is needed to reach the same remaining oil saturation if the polymer viscosity is decreased. The influence of polymer viscosity on total mobility as a function of water saturation is shown in Figure 17c. As expected, the total mobility decreased at elevated polymer viscosity, provided that the water saturation is higher than the connate saturation.

For a stable displacement, the total mobility of the chemical slug should be less than the mobility of the oil bank. The profile of the oil bank and total mobility at $t_{D}=0.20 \mathrm{PV}$ during polymer flooding $\left(\mu_{\mathrm{p}}=70 \mathrm{cP}, \mu_{\mathrm{o}}=72 \mathrm{cP}\right)$ are demonstrated in Figure 17d. This approach can be used for determining the required polymer viscosity for stable displacement. However, designing the optimal polymer viscosity based on fractional flow theory is an iterative process, since the oil bank saturation is also dependent on polymer viscosity. The desired polymer viscosity can be determined by iteratively changing the polymer viscosity in the fractional flow equation such that the polymer bank mobility is smaller than 
the correspondingly generated oil bank mobility. The other approach is to design the polymer viscosity based on the minimum of the total relative mobility curve, which will yield a more conservative design, since the minimal of such curves does not typically reflect the oil bank saturation from fractional flow theory [33]. The illustrated results are only to provide an insight into the importance of mobility control and its influence on oil recovery. In order to optimize the polymer viscosity in the lab or in the field, the results obtained from commercial reservoir simulators, i.e., CMG (Computer Modeling Group, Calgary, AB, Canada) or ECLIPSE (Schlumberger Inc., Houston, TX, USA), would be more reliable and economically feasible.

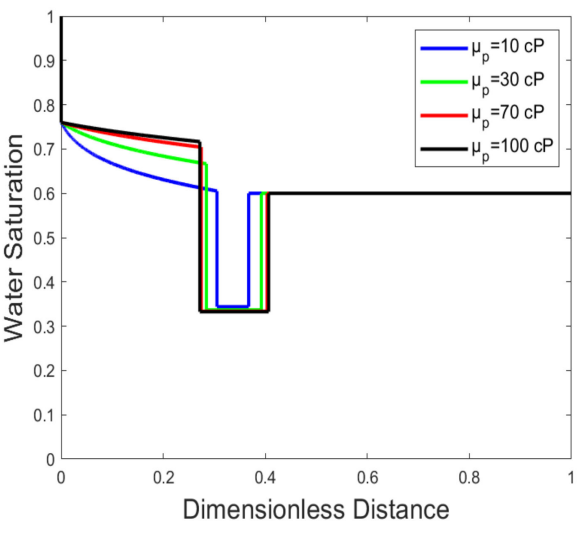

(a)

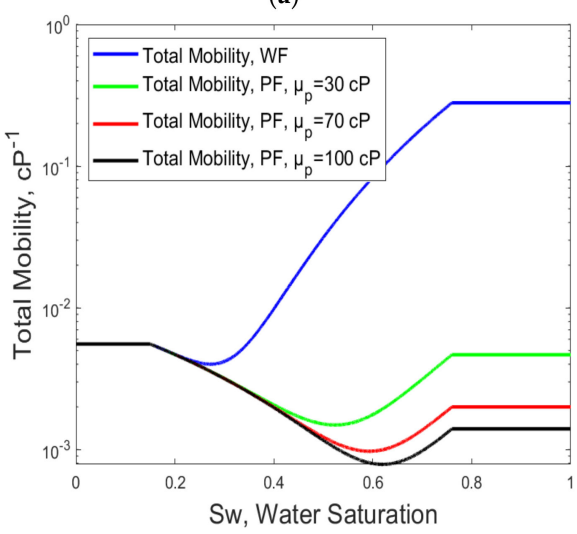

(c)

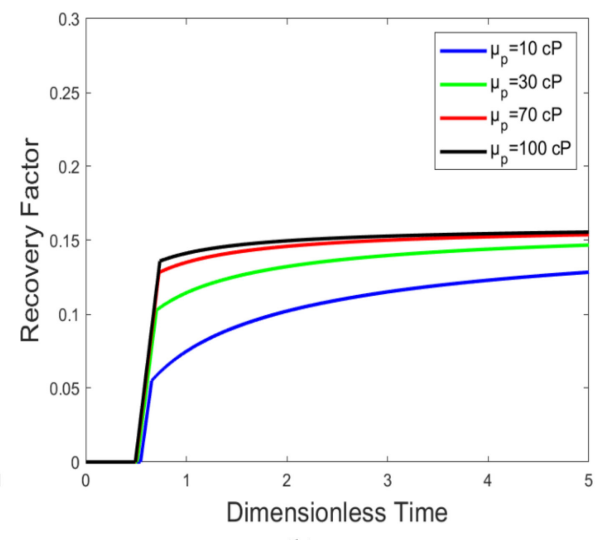

(b)

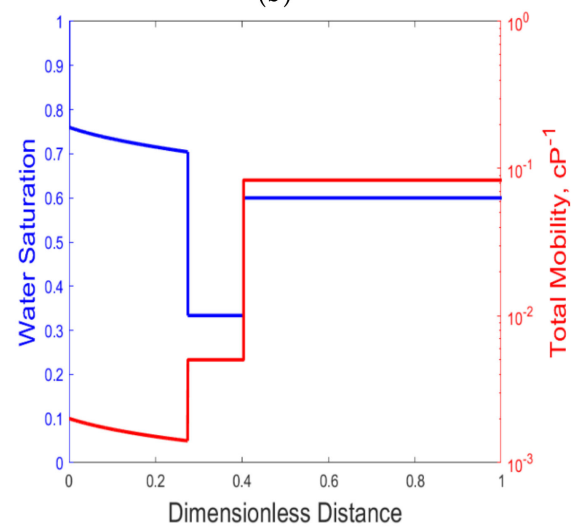

(d)

Figure 17. (a) Comparison of shock front for water flooding and polymer flooding; (b) Incremental oil recovery history during continuous tertiary polymer flooding; (c) Total mobility as a function of water saturation for different polymer viscosity; and (d) Total mobility calculated during polymer flooding, $t_{D}=0.20 \mathrm{PV}, \mu_{p}=70 \mathrm{cP}, \mu_{o}=72 \mathrm{cP}$.

\subsubsection{Influence of Viscoelastic Effect on Residual Oil Saturation}

It has been reported that the water-flooded residual oil saturation can be decreased by using viscoelastic polymer [20,21]. With the increasing Deborah number (De, Equation (33)), a dimensionless number to measure the relative elasticity of a fluid, the residual oil saturation after viscoelastic polymer flooding declines. The other accepted mechanism is that the trapped oil can be dragged out from the dead end by viscoelastic fluid [60]. This mechanism can be validated by fractional flow theory by modifying the residual oil saturation.

$$
D e=\frac{t_{c}}{t_{p}}
$$

where $t_{c}$ and $t_{p}$ stand for the relaxation time and time scale for the process, respectively. 


\subsubsection{Influence of Non-Newtonian Effect}

Polymer solution for EOR application is typically a shear-thinning fluid. The non-Newtonian effect has also been incorporated in the fractional flow model $[20,41]$. This effect may not be neglected, especially when a radial model is used [42].

\subsubsection{Influence of Initial Oil Saturation}

It has been experimentally proven that the water-flooded residual oil saturation can be decreased by an early injection of polymer [19]. It is hypothesized that the dispersion coefficient in the water phase is smaller at larger water saturation, resulting in a more dispersed distribution of the oil phase and a decrease of the sweep efficiency of polymer injections. However, this mechanism has not been validated by the fractional flow theory. We will study the case of secondary recovery by polymer flooding without modifying the residual oil saturation. The initial condition is connate water saturation $\left(S_{i w}=0.15\right)$, and the remaining parameters are the same as those in Section 3.3.1. The construction of the shock front is illustrated in Figure $18 \mathrm{a}, \mathrm{b}$. In this case, the water saturation at the oil bank $\left(S w_{O B}\right)$ is smaller than the water flooding shock front $\left(S w_{w f}\right)$. If $S w_{w f}<S w_{O B}$, there will be a spreading wave between the polymer shock and oil bank.

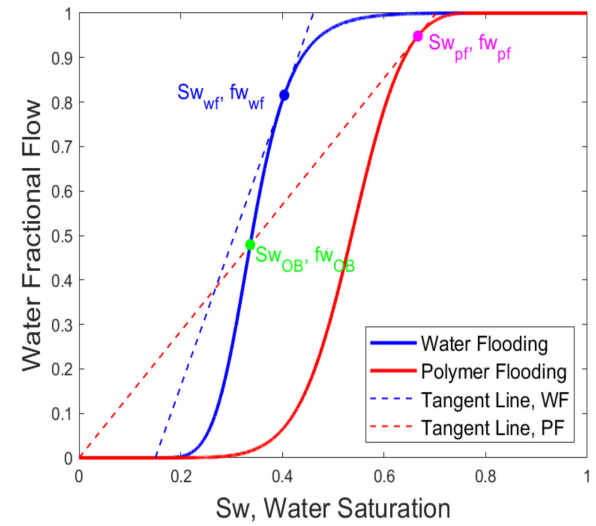

(a)

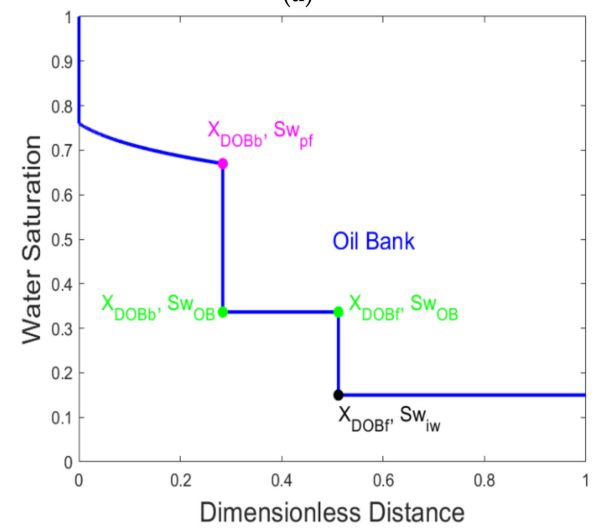

(c)

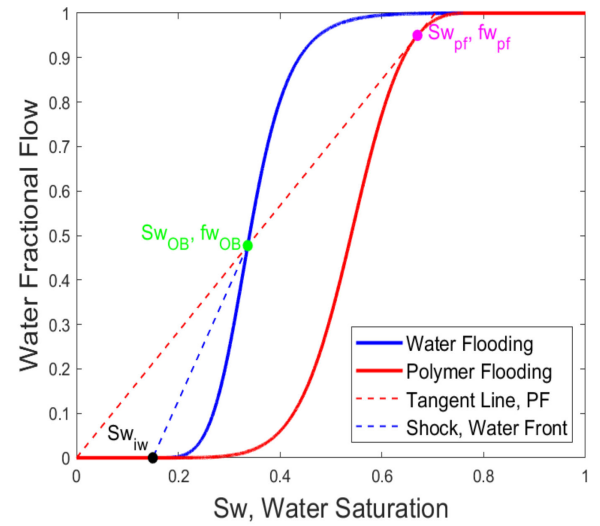

(b)

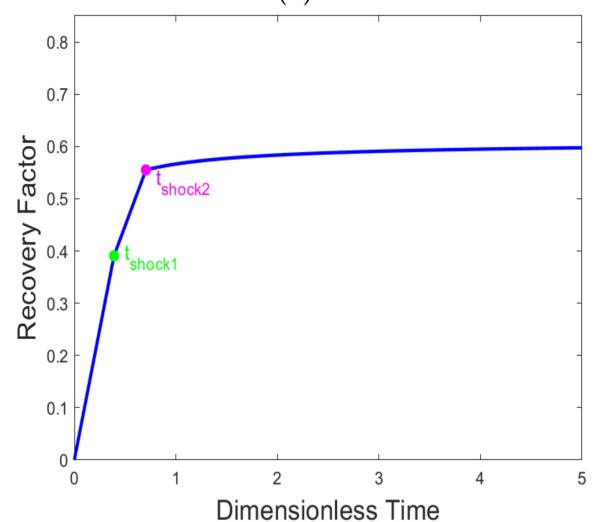

(d)

Figure 18. (a) Comparison of shock front for water flooding and polymer flooding; (b) Construction of shock front during secondary recovery by polymer flooding; (c) Water saturation profile at $t_{D}=0.2$ PV during continuous polymer injection; and (d) Cumulative oil recovery history during secondary recovery by polymer flooding.

Figure $18 \mathrm{c}$ plots the water saturation profile at $t_{D}=0.20 \mathrm{PV}$ and the oil production history during secondary recovery by polymer flooding. Again, two shock fronts can be developed using the same approach described before, with oil saturation $\left(1-S w_{O B}\right)$ at about 0.66 in the oil bank. We can also see that the initial oil saturation will not influence the surfactant front but largely influence the oil 
production history, as shown in Figure 18c,d. Before water breakthrough (approximately 0.39 PV), pure oil is produced; then, the oil cut $\left(1-f w_{O B}\right)$ is reduced to around 0.52 after the first shock breakthrough. After the second shock breakthrough, the oil cut $\left(1-f w_{p f}\right)$ is sharply decreased to 0.05 and then further decreased as the oil tail comes through. The remaining oil saturation is close to residual oil saturation after an injection of $0.71 \mathrm{PV}$ polymer (Figure 18d).

\subsubsection{Influence of Polymer Retention}

Polymer may be adsorbed and (or) precipitated in porous media, due to its interaction with rock and reservoir brine. Moreover, certain lab experiments show that polymer transports faster than water measured by tracer in the permeable medium. This effect is called inaccessible pore volume (IPV). The polymer retention effect and IPV both can be taken account into the retardation factor, which is similar to that is discussed in Section 3.2.2.

The polymer front can be obtained by drawing a tangent line from $\left(-D_{p}, 0\right)$ to the polymer oil fractional flow curve, as shown in Figure 19a. The slope gives the specific velocity of the chemical front [42]. The intersection between the polymer tangent line and water oil fraction flow curve is the oil bank saturation, as illustrated in Figure 19b. The oil bank front can be determined by connecting oil bank saturation to the initial condition, and the velocity is determined by the slope of the shock.

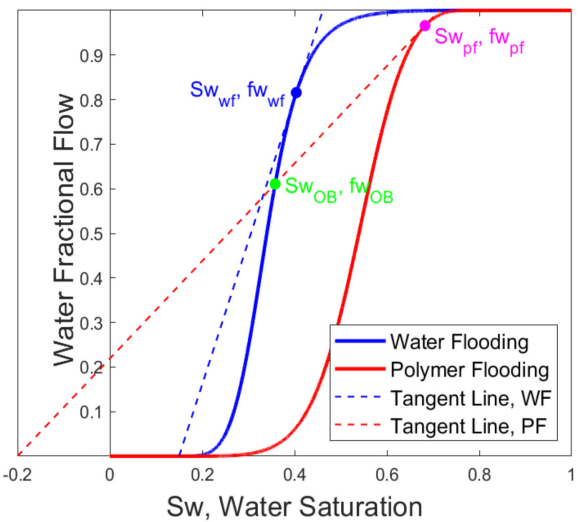

(a)

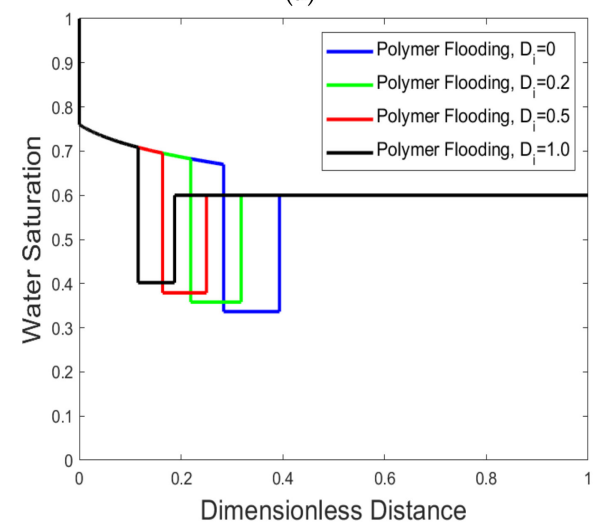

(c)

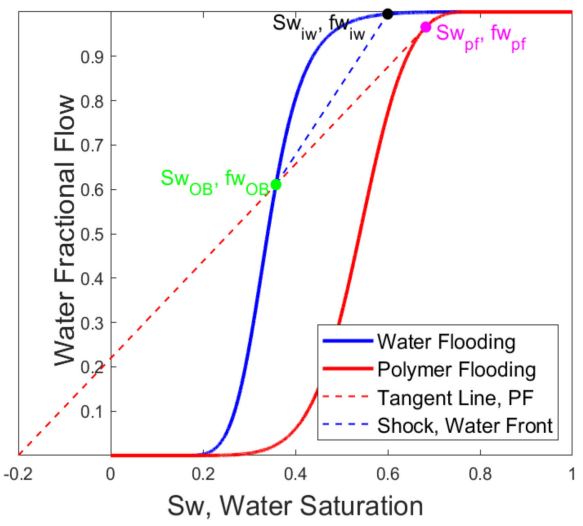

(b)

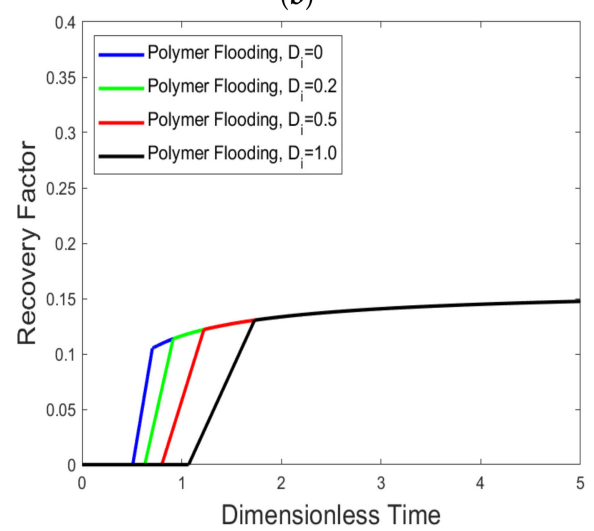

(d)

Figure 19. (a) Comparison of shock front for water flooding and polymer flooding; (b) Construction of shock front during tertiary polymer flooding; (c) Saturation profile at $t_{D}=0.20 \mathrm{PV}$ during tertiary polymer flooding; and (d) Incremental oil recovery history during tertiary polymer flooding at a different retardation factor.

The effect of the retardation factor on tertiary polymer flooding efficiency is shown in Figure 19c,d. We can see that at higher polymer retention, the oil saturation and thereby the oil fractional flow in the oil bank is smaller, the size of oil bank is smaller, and the front as well as back of the oil bank transport 
is slower. Consequently, a higher retention factor will result in a larger retardation of incremental oil production by polymer flooding. More polymer is also needed to be injected into the porous media in order to recover the same amount of oil at a higher retention factor.

\subsubsection{Influence of Polymer Slug Size}

The simulation parameters are the same as those in Section 3.3.1, except that only a slug of polymer would be injected into the porous media. The construction of the shock front for polymer slug injection according to the Hamid method [50] is illustrated in Figure 20a. Figure 20b is the magnified plot of Figure $20 \mathrm{a}$ in the region of the shock front. In this case, the surfactant slug $\left(t_{d, s l u g}\right)$ is $0.30 \mathrm{PV}$, and the total time $\left(t_{d, \text { total }}\right)$ is $1.74 \mathrm{PV}$, i.e., water injection $1.44 \mathrm{PV}$.

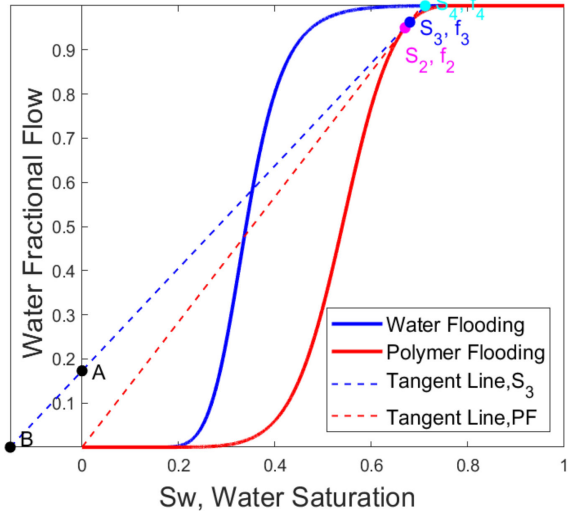

(a)

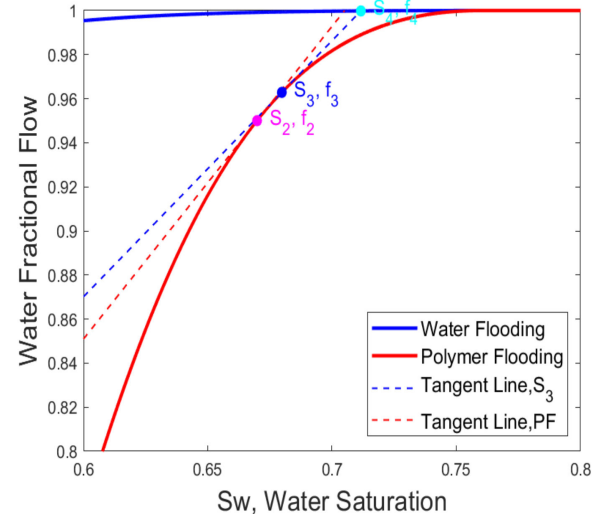

(b)

Figure 20. (a) Determination of the shock front during polymer slug injection; (b) Magnification of figure (a) for determining shock front location, $t_{d, s l u g}=0.30 \mathrm{PV}, t_{d, \text { total }}=1.74 \mathrm{PV}$.

In the following case, a 0.13 PV slug of water drive is injected after an injection of $0.30 \mathrm{PV}$ of polymer. At $t_{d, \text { total }}=0.43 \mathrm{PV}$, the construction of the shock front and water saturation profile is illustrated in Figure 21a,b, respectively.

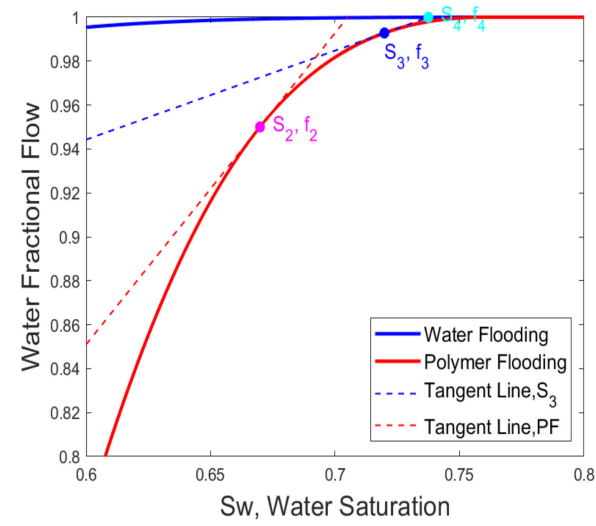

(a)

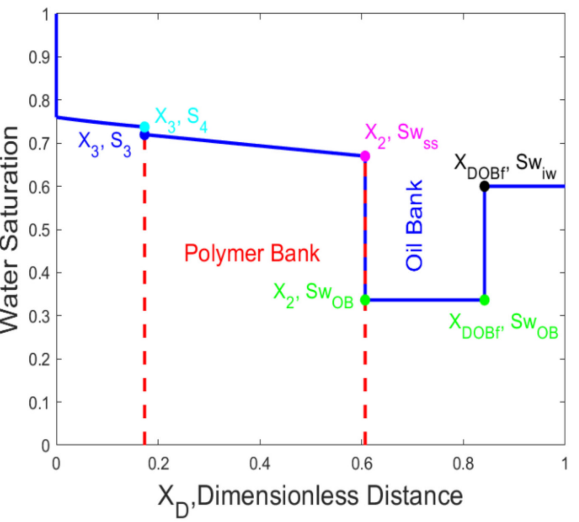

(b)

Figure 21. (a) Determination of the shock front during polymer slug injection; (b) Profile of water saturation and oil bank at $t_{d, \text { slug }}=0.30 \mathrm{PV}, t_{d, \text { total }}=0.43 \mathrm{PV}$.

Similar to what was discussed in Section 3.2.5, if adsorption or dispersion is not considered, the slug size will have a negligible effect on the final oil recovery based on fractional flow theory. It is worth noting that during the water drive that follows after polymer slug injection, the water may penetrate into the polymer bank due to the adverse mobility ratio. This effect was incorporated by a 
semi-analytical method [50]. The effect of slug size on polymer transport with consideration of the adsorption effect has also been reported in the references [51].

\subsection{Alkaline Flooding}

Alkaline flooding can largely benefit from crude oil with a high active soap number [22,46]. A linear alkaline flooding model was developed to study the effect of in situ generated soap on incremental oil recovery using fractional flow theory [34]. This is similar to surfactant flooding and will not be discussed further in this section.

\subsection{Surfactant/Polymer Flooding}

As discussed in the previous section, mobility control is important in low IFT flooding. Laboratory experiments have revealed that surfactant/polymer (SP) flooding is quite efficient and promising in terms of improving oil recovery beyond water flooding [2,27]. We will discuss the analytical simulation of surfactant/polymer flooding by fractional flow theory in this section.

\subsubsection{General Approach}

In surfactant/polymer (SP) flooding, the capillary number may be increased by several magnitudes due to the combination of a reduction in IFT and increase in aqueous phase viscosity. It is hypothesized that the retardation factor for surfactant and polymer are the same, i.e., their transport velocities are equal [31]. Then, no chromatographic separation occurs during the surfactant and polymer transport in porous media $\left(D_{s}=D_{p}\right)$. The relative permeability curves in the presence and absence of surfactant are represented as dashed lines and solid lines respectively in Figure 22a.

The parameters for Corey model correlation are listed in Table 4. Low oil viscosity is used in the demonstrated case. Figure $22 \mathrm{~b}$ is to demonstrate the fractional flow curves in terms of water flooding and SP flooding at a high capillary number. The initial condition before conducting SP flooding is water-flooded residual oil saturation $\left(S_{o i}=0.4\right)$ in the following example simulation case. Similar to the discussion before, two shocks can be then constructed during tertiary surfactant-polymer flooding, as shown in Figure 22c. The saturation profile after the injection of 0.20 PV SP slug is elucidated in Figure 22d. A large oil bank $\left(1-S w_{O B}\right)$ with high oil saturation (approximately 0.54$)$ is formed in this example case, with oil fractional flow $\left(1-f w_{O B}\right)$ at 0.52 . Behind the chemical shock, it is a region of spreading waves with constant surfactant/polymer concentration.

\subsubsection{Influence of Surfactant/Polymer Retention}

As for the case of surfactant-polymer flooding with retention, the construction of the shock front is shown in Figure 23a. The initial condition before SP flooding is the same as the case without considering the effect of retention. The retardation factor is 0.20 and other parameters are the same as described in Section 3.5.1. The influence of retention on oil production history during SP flooding is exhibited in Figure 23b. Again, due to chemical retention, the oil production will be delayed and more chemicals need to be injected into the porous medium.

Table 4. Corey model parameters for water-oil two-phase relative permeability in the presence and absence of surfactant and polymer.

\begin{tabular}{cccccccc}
\hline \multicolumn{6}{c}{ Water-Oil Two-Phase Relative Permeability in the Absence of Surfactant/Polymer } \\
\hline$k_{r w}^{0}$ & $k_{r o}^{0}$ & $S_{r w}$ & $S_{r o}$ & $n_{w o}$ & $n_{o}$ & $\mu_{w}$ & $\mu_{o}$ \\
\hline 0.14 & 0.40 & 0.15 & 0.24 & 4 & 2 & 0.5 & 5 \\
\hline \multicolumn{6}{l}{ Water-Oil Two-Phase } & Relative & Permeability in the Presence of Surfactant/Polymer \\
\hline$k_{r w}^{0}$ & $k_{r o}^{0}$ & $S_{r w}$ & $S_{r o}$ & $n_{w o}$ & $n_{o}$ & $\mu_{p}$ & $\mu_{o}$ \\
\hline 0.40 & 1.00 & 0.15 & 0.05 & 4.0 & 1.5 & 10 & 5 \\
\hline
\end{tabular}




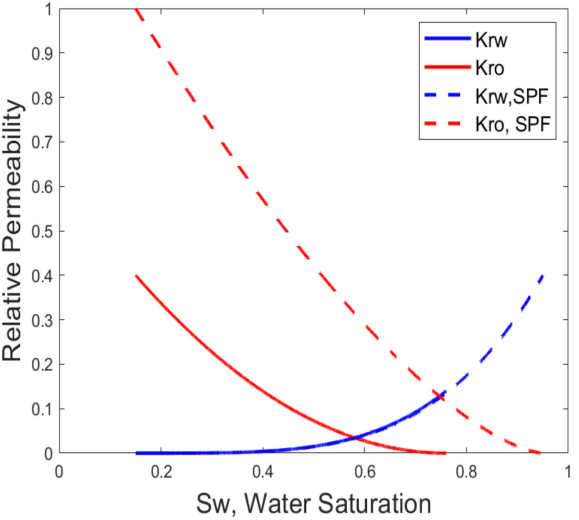

(a)

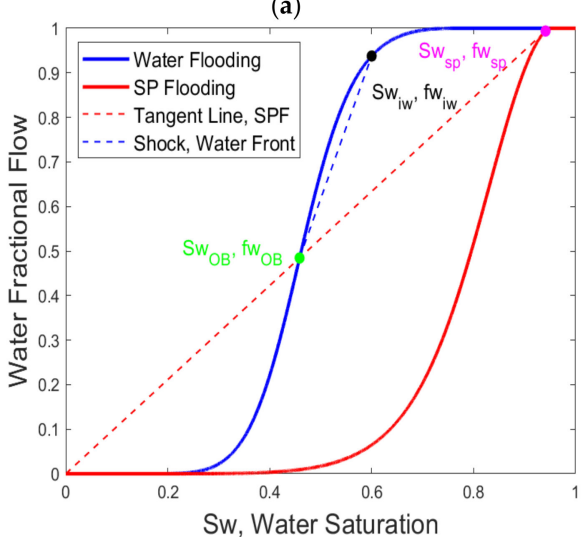

(c)

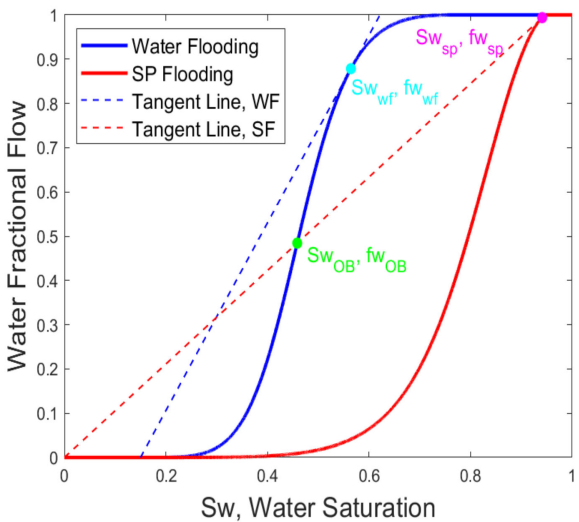

(b)

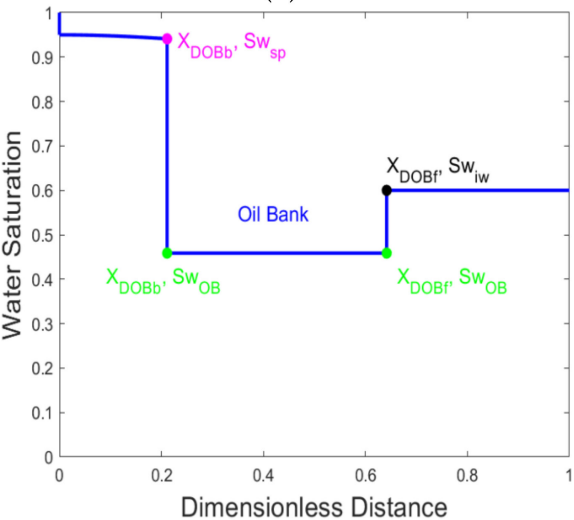

(d)

Figure 22. (a) Water-oil two-phase relative permeability for water flooding and surfactant/polymer (SP) flooding; (b) Construction of shock front for water flooding and SP flooding; (c) Construction of shock front for continuous tertiary SP flooding, no adsorption; and (d) Water saturation profile at $t_{D}=$ 0.20 PV during SP flooding, no adsorption.

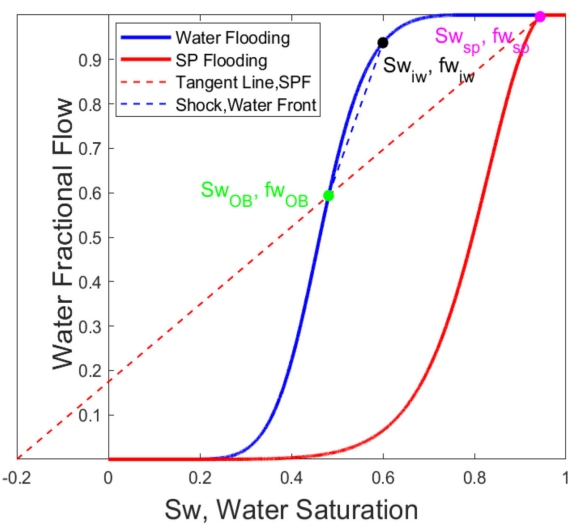

(a)

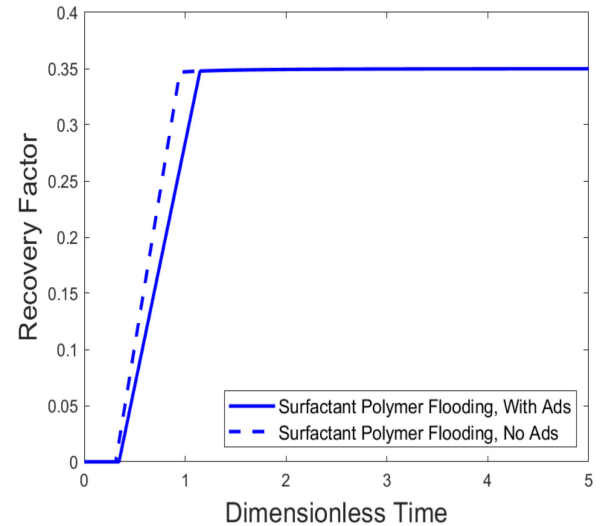

(b)

Figure 23. (a) Construction of shock front for water flooding and surfactant/polymer flooding, with adsorption; and (b) Comparison of cumulative oil recovery during SP flooding, between no adsorption and $D_{i}=0.2$.

\subsubsection{Piston-Like Displacement}

At a desirable case, the relative permeability curves will be diagonal lines and the fractional flow curve is convex to the diagonal line, as shown in Figure 24a,b [3,58]. If adequate mobility control is provided simultaneously, the displacement would be piston-like, i.e., there is no spreading wave 
between the boundary condition to the surfactant shock front. The simulation parameters are listed in Table 5.

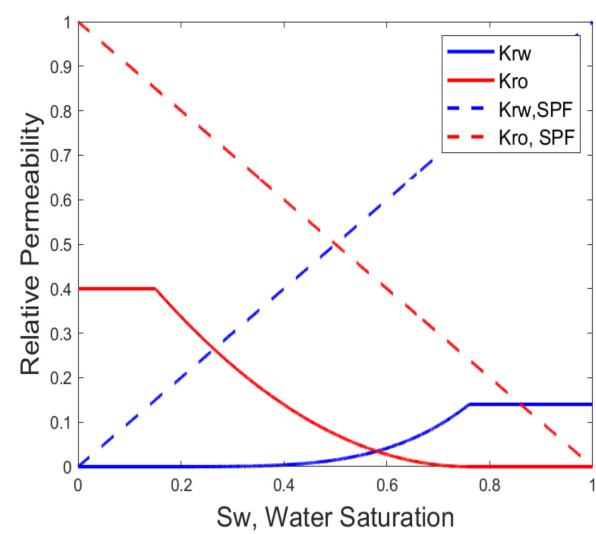

(a)

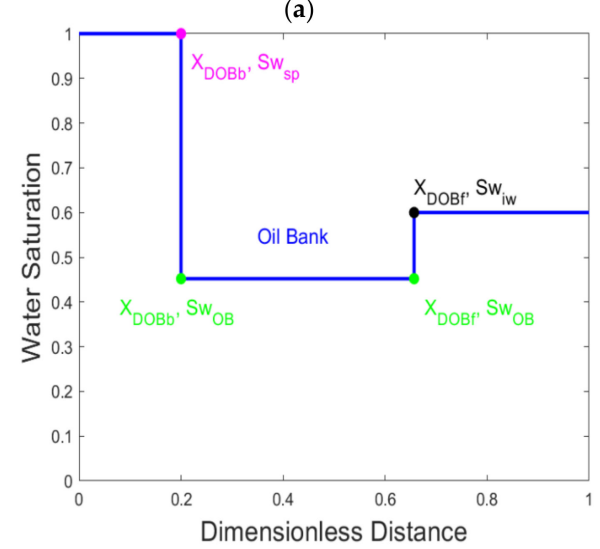

(c)

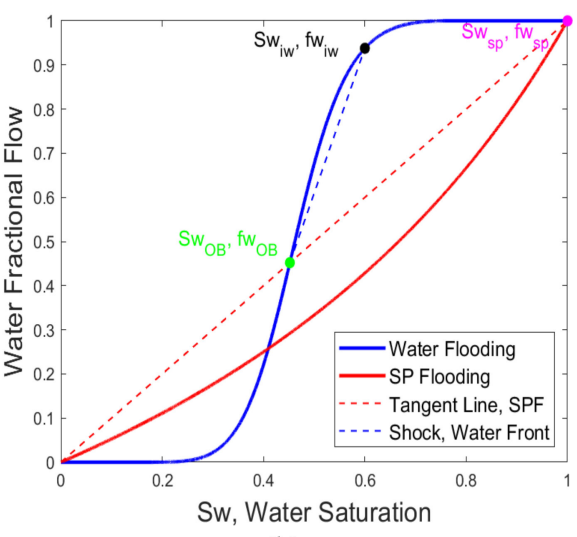

(b)

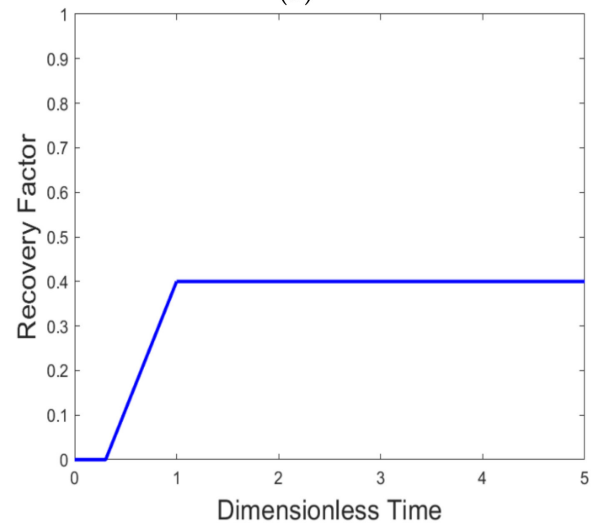

(d)

Figure 24. (a) Water-oil two-phase relative permeability for water flooding and piston-like displacement; (b) Construction of shock front for water flooding and piston displacement; (c) Water saturation profile at $t_{D}=0.2$ PV for piston-like SP flooding; and (d) Cumulative oil recovery during piston-like SP flooding.

Table 5. Corey model parameters for water flooding and piston-like displacement in the presence of surfactant/polymer.

\begin{tabular}{|c|c|c|c|c|c|c|c|}
\hline \multicolumn{8}{|c|}{ Water-Oil Two-Phase Relative Permeability for Water Flooding } \\
\hline$k_{r w}^{0}$ & $k_{r o}^{0}$ & $S_{r w}$ & $S_{r o}$ & $n_{w}$ & $n_{0}$ & $\mu_{w}$ & $\mu_{0}$ \\
\hline 0.14 & 0.40 & 0.15 & 0.24 & 4 & 2 & 0.5 & 5 \\
\hline \multicolumn{8}{|c|}{ Water-Oil Relative Permeability for Piston-Like SP Flooding } \\
\hline$k_{r w}^{0}$ & $k_{r o}^{0}$ & $S_{r w}$ & $S_{r o}$ & $n_{w}$ & $n_{0}$ & $\mu_{p}$ & $\mu_{0}$ \\
\hline 1.00 & 1.00 & 0.00 & 0.00 & 1.0 & 1.0 & 10 & 5 \\
\hline
\end{tabular}

In the following example case, the initial condition is water-flooded residual oil saturation $\left(S_{o i}=0.40\right)$. Figure $24 \mathrm{~b}, \mathrm{c}$ show the graphical construction of shock fronts and the saturation profile at $0.20 \mathrm{PV}$, respectively.

As can be seen in Figure 24c, there are only two shocks, one of which is from oil bank saturation to initial oil saturation and the other is at the leading chemical front from the injection chemicals to connate water. The oil saturation $\left(1-S w_{O B}\right)$ and oil fractional flow $\left(1-f w_{O B}\right)$ in the oil bank are both at 0.45 . The front bank of the surfactant and polymer, i.e., back shock of the oil bank will have unity velocity. After the chemical shock breakthrough, no oil will be produced, and the final oil recovery would be $100 \%$ original oil in place (OOIP) after the injection of $1.0 \mathrm{PV}$ of chemicals. In this case, 
the recovery factor will be linear after the oil bank front breakthroughs and then immediately reach plateau, as illustrated in Figure 24d.

\section{Conclusions}

Fractional flow theory still serves as a powerful tool for understanding the mechanisms of the Chemical Enhanced Oil Recovery (CEOR) process. Although several assumptions are made in order to reach the analytical solution, different chemical flooding mechanisms can still be studied by fractional flow theory. The main conclusions are summarized as the following:

(1) For higher oil viscosity, water breakthroughs are earlier during water flooding. Furthermore, more water needs to be injected in order to reach the water-flooded residual oil saturation. If an infinite amount of water is injected, the remaining oil saturation will be close to the water-flooded residual oil saturation;

(2) The surfactant (or polymer) adsorption and partition into oleic phase would result in severe retardation in its transport in porous media. Therefore, the promising surfactant formulation should have a small adsorption and small partition coefficient (into oil);

(3) Mobility control, i.e., polymer viscosity, is of great significance in designing a successful chemical EOR process. The desired polymer viscosity needed to reach a stable displacement can be obtained by the fractional flow theory;

(4) For chemical slug injection, if the adsorption effect (surfactant flooding) or viscous fingering effect (polymer flooding) is not considered, the slug size will have a negligible effect on the final oil recovery;

(5) The piston-like displacement is quite efficient in terms of sweep efficiency, while the displacement efficiency under ultralow interfacial tension is highly effective. If sufficient mobility control and ultralow IFT are provided simultaneously, the displacement front will transport at a dimensionless velocity of unity.

Supplementary Materials: The following are available online at http://www.mdpi.com/2073-4441/12/8/2195/s1, s1: Matlab code for analytical simulation using Buckley-Leverett theory. The Matlab code for analytical simulation using Buckley-Leverett theory can be found in the supplementary materials of this article.

Author Contributions: Conceptualization, D.G. and L.D.; methodology, L.D., Q.W. and L.Z.; All authors worked together on writing the original draft, reviewing, and editing to finalize the manuscript; project administration, D.G.; funding acquisition, D.G. All authors have read and agreed to the published version of the manuscript.

Funding: This research was funded by Qatar Foundation, Qatar National Research Fund, grant number NPRP 10-1214-160025.

Acknowledgments: We acknowledge the technical support from the Department of Petroleum Engineering, Texas A\&M University at Qatar.

Conflicts of Interest: The authors declare no conflict of interest. The funders had no role in the design of the study; in the collection, analyses, or interpretation of data; in the writing of the manuscript, or in the decision to publish the results.

\section{Nomenclature}

$A$

$A_{i}$

$\mathrm{B}$

$\hat{C}_{i}$

$C_{i}$

$C_{s o}$

$C_{s w}$

$C_{S D}$

$t_{d, \text { slug }}$
A parameter in Equation (25)

Adsorption of component i per unit mass of rock, $\mathrm{mg} / \mathrm{g}$ rock

A parameter in Equation (26)

Adsorption in units of amount of adsorbed per unit pore volume, $\mathrm{mg} / \mathrm{PV}$

Concentration of component $\mathrm{i}$ in aqueous phase, $\mathrm{g} / \mathrm{L}$

Surfactant concentration in oil phase, $\mathrm{g} / \mathrm{L}$

Surfactant concentration in aqueous phase, $\mathrm{g} / \mathrm{L}$

Dimensionless surfactant concentration

Dimensionless injected surfactant slug size, PV 
$t_{d, \text { total }} \quad$ Total dimensionless time, PV

De Deborah number

$D_{i} \quad$ General dimensionless retardation term, PV

$E_{R} \quad$ Oil recovery factor, dimensionless

$E_{j} \quad$ Corey exponent for relative permeability during chemical flooding

$f_{j} \quad$ Fractional flow of phase $\mathrm{j}$, dimensionless

$f w_{O B} \quad$ Water fractional flow in the oil bank

$M \quad$ Water oil mobility ratio

$\mathrm{N}_{c a} \quad$ Capillary number, dimensionless

$\vec{k} \quad$ Permeability of rock, $\mathrm{mD}$

$k_{r j} \quad$ Relative permeability of phase $\mathrm{j}, \mathrm{j}=\mathrm{w}$ or $\mathrm{o}$

$k_{r j}^{0}$

$k_{r j c}$

$k_{r j c}^{0}$

$L$

$n_{j}$

$S_{i w}$

$S_{o i}$

$S_{E j}$

$S_{n j}$

$S_{r j}$

$S_{j R}$

$S_{r j c}$

$S_{\text {rjc }}$

$S w_{O B}$

$\mathrm{t}$

$t_{D}$

$t_{c}$

$\frac{t_{p}}{\vec{u}_{j}}$

$\vec{u}_{j}$

$\stackrel{\mu_{j}}{\vec{u}_{t}}$

$u_{t} \rightarrow B C$

$\vec{u}^{B C}$

$\mathrm{x}$

$x_{D}$

$x_{D O B b}$

End point relative permeability of phase $\mathrm{j}$ in two phase flow, $\mathrm{j}=\mathrm{w}$ or $\mathrm{o}$

Relative permeability of phase $\mathrm{j}$ during chemical flooding

End point relative permeability of phase $\mathrm{j}$ during chemical flooding

Total distance, $\mathrm{m}$

Corey exponents for phase $j$

Initial water saturation

Initial oil saturation

Normalized phase saturation during water flooding

Normalized phase saturation during water flooding

Residual saturation of phase $\mathrm{j}, \mathrm{j}=\mathrm{w}$ or $\mathrm{o}$, dimensionless

Normalized phase saturation during chemical flooding

Residual saturation of phase $\mathrm{j}$ during chemical flooding

Residual saturation during chemical flooding

Water saturation in the oil bank

Time, $\mathrm{s}$

Dimensionless time

Relaxation time, $\mathrm{s}$

Time scale for the process, $\mathrm{s}$

Superficial velocity of phase $\mathrm{j}, \mathrm{m} / \mathrm{s}$

Dynamic viscosity of phase $\mathrm{j}, \mathrm{cP}$

Total superficial velocity of phases, $\mathrm{m} / \mathrm{s}$

Total superficial velocity of phases at boundary condition, $\mathrm{m} / \mathrm{s}$

Distance, $\mathrm{m}$

Dimensionless distance

$x_{D O B f}$

Dimensionless distance of the back of oil bank

$\rho_{S S}$

Dimensionless distance of the front of oil bank

Density of solid or porous media, $\mathrm{g} / \mathrm{cm}^{3}$

$\Phi_{j} \quad$ Flow potential of phase j, dimensionless

$\varnothing_{i} \quad$ Accessible porosity of phase $\mathrm{j}$, dimensionless

$\varnothing \quad$ Porosity, dimensionless

$\gamma_{o w}$

Water oil interfacial tension, $\mathrm{mN} / \mathrm{m}$

Subscripts

$i$

Component $\mathrm{i}, \mathrm{i}=$ surfactant $(\mathrm{s})$ or polymer $(\mathrm{p})$

j

$\mathrm{t}$

$\mathrm{D}$

The $j$ phase, oil (o) or water $(w)$

Total phases

Dimensionless

Shock At the location of shock

sS

Surfactant shock

I.C. Initial condition

B.T. Dimensionless time of water breakthrough, PV

Superscripts

0

End point relative permeability

$\mathrm{BC}$

Boundary condition 


\section{References}

1. Alvarado, V.; Manrique, E. Enhanced oil recovery: An update review. Energies 2010, 3, 1529-1575. [CrossRef]

2. Hirasaki, G.; Miller, C.A.; Puerto, M. Recent Advances in Surfactant EOR. Soc. Pet. Eng. J. 2011, 16, 898-907. [CrossRef]

3. Lake, L.W.; Johns, R.; Rossen, W.R.; Pope, G.A. Fundamentals of Enhanced oil Recovery; Society of Petroleum Engineers: Richardson, TX, USA, 2014.

4. Stegemeier, G.L. Improved oil Recovery by Surfactant and Polymer Flooding; Shah, D.O., Ed.; Elsevier: New York, NY USA, 1977. [CrossRef]

5. Sorbie, K.S. Polymer-Improved Oil Recovery; Springer Science \& Business Media: Edinburgh, UK, 2013. [CrossRef]

6. Chatzis, I.; Morrow, N.R. Correlation of capillary number relationships for sandstone. Soc. Pet. Eng. J. 1984, 24, 555-562. [CrossRef]

7. Pennell, K.D.; Pope, G.A.; Abriola, L.M. Influence of viscous and buoyancy forces on the mobilization of residual tetrachloroethylene during surfactant flushing. Environ. Sci. Technol. 1996, 30, 1328-1335. [CrossRef]

8. Morrow, N.R. Wettability and its effect on oil recovery. J. Pet. Technol. 1990, 42, 1-476. [CrossRef]

9. Zhang, P.; Tweheyo, M.T.; Austad, T. Wettability alteration and improved oil recovery by spontaneous imbibition of seawater into chalk: Impact of the potential determining ions $\mathrm{Ca}^{2+}, \mathrm{Mg}^{2+}$, and $\mathrm{SO}_{4}{ }^{2-}$. Colloids Surf. A Physicochem. Eng. Asp. 2007, 301, 199-208. [CrossRef]

10. Zhou, X.; Morrow, N.R.; Ma, S. Interrelationship of wettability, initial water saturation, aging time, and oil recovery by spontaneous imbibition and waterflooding. In Proceedings of the SPE/DOE Improved Oil Recovery Symposium, Tulsa, OK, USA, 21-24 April 1996. [CrossRef]

11. Vledder, P.; Gonzalez, I.E.; Carrera Fonseca, J.C.; Wells, T.; Ligthelm, D.J. Low salinity water flooding: Proof of wettability alteration on a field wide scale. In Proceedings of the SPE Improved Oil Recovery Symposium, Tulsa, OK, USA, 24-28 April 2010. [CrossRef]

12. Morrow, N.R.; Tang, G.Q.; Valat, M.; Xie, X. Prospects of improved oil recovery related to wettability and brine composition. J. Pet. Sci. Eng. 1998, 20, 267-276. [CrossRef]

13. Buckley, J.S.; Takamura, K.; Morrow, N.R. Influence of electrical surface charges on the wetting properties of crude oils. SPE Reserv. Eng. 1989, 4, 332-340. [CrossRef]

14. Buckley, J.S.; Liu, Y.; Xie, X.; Morrow, N.R. Asphaltenes and crude oil wetting-the effect of oil composition. SPE J. 1997, 2, 107-119. [CrossRef]

15. Hirasaki, G.; Zhang, D.L. Surface chemistry of oil recovery from fractured, oil-wet, carbonate formations. SPE J. 2004, 9, 151-162. [CrossRef]

16. Dubey, S.T.; Doe, P.H. Base number and wetting properties of crude oils. SPE Reserv. Eng. 1993, 8, $195-200$. [CrossRef]

17. Jadhunandan, P.P.; Morrow, N.R. Effect of wettability on waterflood recovery for crude-oil/brine/rock systems. SPE Reserv. Eng. 1995, 10, 40-46. [CrossRef]

18. Sheng, J.J.; Leonhardt, B.; Azri, N. Status of polymer-flooding technology. J. Can. Pet. Technol. 2015, 54, 116-126. [CrossRef]

19. Juárez-Morejón, J.L.; Bertin, H.; Omari, A.; Hamon, G.; Cottin, C.; Morel, D.; Bourdarot, G. A New Approach to Polymer Flooding: Effects of Early Polymer Injection and Wettability on Final Oil Recovery. Soc. Pet. Eng. J. 2019, 24, 129-139. [CrossRef]

20. Koh, H.; Lee, V.B.; Pope, G.A. Experimental Investigation of the Effect of Polymers on Residual Oil Saturation. Soc. Pet. Eng. J. 2018, 23, 1-17. [CrossRef]

21. Qi, P.; Lashgari, H.; Luo, H.; Delshad, M.; Pope, G.; Balhoff, M. Simulation of Viscoelastic Polymer Flooding-From the Lab to the Field. In Proceedings of the SPE Annual Technical Conference and Exhibition, Dallas, TX, USA, 24-26 September 2018. [CrossRef]

22. Ding, L.; Zhang, G.; Behling, J.; Lopez-Salinas, J.L.; Ge, J.; Puerto, M.C.; Hirasaki, G.J.; Miller, C.A. Determination of the active soap number of crude oil and soap partitioning behavior. Energy Fuels 2016, 30, 10106-10116. [CrossRef]

23. Bourrel, M.; Schechter, R.S. Microemulsions and Related Systems: Formulation, Solvency, and Physical Properties; Surfactant Science Series; Marcel Dekker: New York, NY, USA, 1988; Volume 30.

24. Sheng, J.J. Status of surfactant EOR technology. Petroleum 2015, 1, 97-105. [CrossRef] 
25. Levitt, D.; Jackson, A.; Heinson, C.; Britton, L.N.; Malik, T.; Dwarakanath, V.; Pope, G.A. Identification and evaluation of high-performance EOR surfactants. In Proceedings of the SPE/DOE Symposium on Improved Oil Recovery, Tulsa, OK, USA, 22-26 April 2006. [CrossRef]

26. Flaaten, A.; Nguyen, Q.P.; Pope, G.A.; Zhang, J. A systematic laboratory approach to low-cost, high-performance chemical flooding. In Proceedings of the SPE Symposium on Improved Oil Recovery, Tulsa, OK, USA, 20-23 April 2008. [CrossRef]

27. Samanta, A.; Ojha, K.; Sarkar, A.; Mandal, A. Surfactant and surfactant-polymer flooding for enhanced oil recovery. Adv. Pet. Explor. Dev. 2011, 2, 13-18. [CrossRef]

28. Aziz, K. Petroleum Reservoir Simulation; Applied Science Publishers: London, UK, 1979.

29. Peaceman, D.W. Fundamentals of Numerical Reservoir Simulation; Elsevier: Houston, TX, USA, 2000.

30. Buckley, S.E.; Leverett, M.C. Mechanism of fluid displacement in sands. Trans. AIME 1942, 146, $107-116$. [CrossRef]

31. Pope, G.A. The application of fractional flow theory to enhanced oil recovery. Soc. Pet. Eng. J. 1980, 20, 191-205. [CrossRef]

32. Larson, R.G.; Hirasaki, G.J. Analysis of the Physical Mechanisms in Surfactant Flooding. SPEJ 1976, 6003. [CrossRef]

33. Farajzadeh, R.; Wassing, B.L.; Lake, L.W. Insights into design of mobility control for chemical enhanced oil recovery. Energy Rep. 2019, 5, 570-578. [CrossRef]

34. DeZabala, E.F.; Vislocky, J.M.; Rubin, E.; Radke, C.J. A chemical theory for linear alkaline flooding. Soc. Pet. Eng. J. 1982, 22, 245-258. [CrossRef]

35. Walsh, M.P.; Lake, L.W. Applying fractional flow theory to solvent flooding and chase fluids. J. Pet. Sci. Eng. 1989, 2, 281-303. [CrossRef]

36. Han, H.; Li, T.; Song, H.; Wang, Y.; Killough, J. Experimental research on remaining oil distribution and recovery performance after immiscible and miscible $\mathrm{CO}_{2}$-WAG injection by direct visualisation. Int. J. Oilgas Coal Technol. 2017, 15, 47-59. [CrossRef]

37. Song, H.; Huang, G.; Li, T.; Zhang, Y.; Lou, Y. Analytical model of $\mathrm{CO}_{2}$ storage efficiency in saline aquifer with vertical heterogeneity. J. Nat. Gas Sci. Eng. 2014, 18,77-89. [CrossRef]

38. Ashoori, E.; van der Heijden, T.; Rossen, W. Fractional-flow theory of foam displacements with oil. SPE J. 2010, 15, 260-273. [CrossRef]

39. Jerauld, G.R.; Webb, K.J.; Lin, C.Y.; Seccombe, J. Modeling low-salinity water flooding. In Proceedings of the SPE Annual Technical Conference and Exhibition, San Antonio, TX, USA, 24-27 September 2006. [CrossRef]

40. Wang, J.; Song, H.; Wang, Y. Investigation on the micro-flow mechanism of enhanced oil recovery by low-salinity water flooding in carbonate reservoir. Fuel 2020, 266, 117156. [CrossRef]

41. Rossen, W.R.; Venkatraman, A.; Johns, R.T.; Kibodeaux, K.R.; Lai, H.; Tehrani, N.M. Fractional flow theory applicable to non-Newtonian behavior in EOR processes. Transp. Porous Media 2011, 89, 213-236. [CrossRef]

42. Sun, L.; Li, B.; Jiang, H.; Li, Y.; Jiao, Y. An Injectivity Evaluation Model of Polymer Flooding in Offshore Multilayer Reservoir. Energies 2019, 12, 1444. [CrossRef]

43. Corey, A.T. The interrelation between gas and oil relative Permeabilities. Prod. Mon. 1954, 19, $38-41$.

44. Adenutsi, C.D.; Li, Z.; Lai, F.; Hama, A.E.; Aggrey, W.N. Pore pressure variation at constant confining stress on water-oil and silica nanofluid-oil relative permeability. J. Pet. Explor. Prod. Technol. 2019, 9, 2065-2079. [CrossRef]

45. Welge, H.J. A simplified method for computing oil recovery by gas or water drive. J. Pet. Technol. 1952, 4, 91-98. [CrossRef]

46. Ding, L.; Zhai, X.; Puerto, M.C.; Miller, C.A.; Hirasaki, G.J. Alkaline surfactant polymer ASP process for shaley formation with pyrite. In Proceedings of the SPE Improved Oil Recovery Conference, Tulsa, OK, USA, 14-18 April 2018. [CrossRef]

47. Lu, J.; Britton, C.; Solairaj, S.; Liyanage, P.J.; Kim, D.H.; Adkins, S.; Pope, G.A. Novel large-hydrophobe alkoxy carboxylate surfactants for enhanced oil recovery. SPE J. 2014, 19, 1-024. [CrossRef]

48. Hirasaki, G.J.; Van Domselaar, H.R.; Nelson, R.C. Evaluation of the salinity gradient concept in surfactant flooding. Soc. Pet. Eng. J. 1983, 23, 486-500. [CrossRef]

49. Bedrikovetsky, P. Mathematical Theory of Oil and Gas Recovery: With Applications to Ex-USSR Oil and Gas Fields; Springer Science \& Business Media: Dordrecht, The Netherlands, 2013; Volume 4. [CrossRef] 
50. Hamid, S.A.; Muggeridge, A. HAnalytical solution of polymer slug injection with viscous fingering. Comput. Geosci. 2018, 22, 711-723. [CrossRef]

51. Ribeiro, P.M.; Pires, A.P. The displacement of oil by polymer slugs considering adsorption effects. In Proceedings of the SPE Annual Technical Conference and Exhibition, Denver, CO, USA, 21-24 September 2008. [CrossRef]

52. Helfferich, F.G. Theory of multicomponent, multiphase displacement in porous media. Soc. Pet. Eng. J. 1981, 21, 51-62. [CrossRef]

53. Hirasaki, G.J. Application of the theory of multicomponent, multiphase displacement to three-component, two-phase surfactant flooding. Soc. Pet. Eng. J. 1981, 21, 191-204. [CrossRef]

54. Li, T.; Song, H.; Wang, J.; Wang, Y.; Killough, J. An analytical method for modeling and analysis gas-water relative permeability in nanoscale pores with interfacial effects. Int. J. Coal Geol. 2016, 159, 71-81. [CrossRef]

55. Jin, L.; Li, Z.; Jamili, A.; Kadhum, M.; Lu, J.; Shiau, B.J.; Harwell, J.H.; Delshad, M. An Analytical Solution for Three-Component, Two-Phase Surfactant Flooding Dependent on the Hydrophilic/Lipophilic-Difference Equation and the Net-Average-Curvature Equation of State. SPE J. 2017, 22, 1-424. [CrossRef]

56. Seto, C.J.; Jessen, K.; Orr, F.M. A multicomponent, two-phase-flow model for $\mathrm{CO}_{2}$ storage and enhanced coalbed-methane recovery. SPE J. 2009, 14, 30-40. [CrossRef]

57. Liu, S.; Zhang, D.; Yan, W.; Puerto, M.; Hirasaki, G.J.; Miller, C.A. Favorable Attributes of Alkaline-Surfactant-Polymer Flooding. SPE J. 2008, 13, 5-16. [CrossRef]

58. Mohammadi, H.; Delshad, M.; Pope, G.A. Mechanistic modeling of alkaline/surfactant/polymer floods. SPE Reserv. Eval. Eng. 2009, 12, 518-527. [CrossRef]

59. Pope, G.A. Recent developments and remaining challenges of enhanced oil recovery. J. Pet. Technol. 2011, 63, 65-68. [CrossRef]

60. Wang, D.; Cheng, J.; Xia, H.; Li, Q.; Shi, J. Viscous-elastic fluids can mobilize oil remaining after water-flood by force parallel to the oil-water interface. In Proceedings of the SPE Asia Pacific Improved Oil Recovery Conference, Kuala Lumpur, Malaysia, 6-9 October 2001. [CrossRef]

(C) 2020 by the authors. Licensee MDPI, Basel, Switzerland. This article is an open access article distributed under the terms and conditions of the Creative Commons Attribution (CC BY) license (http://creativecommons.org/licenses/by/4.0/). 